\title{
Magnetic Solid-Phase Extraction of Organic Compounds Based on Graphene Oxide Nanocomposites
}

\author{
Natalia Manousi ${ }^{1,2}\left({ }^{1}\right.$, Erwin Rosenberg ${ }^{2}$, Eleni Deliyanni ${ }^{3}\left(\mathbb{D}\right.$, George A. Zachariadis $^{1}(\mathbb{D}$ and \\ Victoria Samanidou ${ }^{1, *(D)}$ \\ 1 Laboratory of Analytical Chemistry, Department of Chemistry, Aristotle University of Thessaloniki, \\ 54124 Thessaloniki, Greece \\ 2 Institute of Chemical Technologies and Analytics, Vienna University of Technology, 1060 Vienna, Austria \\ 3 Laboratory of Chemical and Environmental Technology, Department of Chemistry, Aristotle University of \\ Thessaloniki, 54124 Thessaloniki, Greece \\ * Correspondence: samanidu@chem.auth.gr; Tel.: +30-2310-997698
}

Academic Editor: Verónica Pino

Received: 29 January 2020; Accepted: 27 February 2020; Published: 4 March 2020

\begin{abstract}
Graphene oxide (GO) is a chemical compound with a form similar to graphene that consists of one-atom-thick two-dimensional layers of $\mathrm{sp}^{2}$-bonded carbon. Graphene oxide exhibits high hydrophilicity and dispersibility. Thus, it is difficult to be separated from aqueous solutions. Therefore, functionalization with magnetic nanoparticles is performed in order to prepare a magnetic GO nanocomposite that combines the sufficient adsorption capacity of graphene oxide and the convenience of magnetic separation. Moreover, the magnetic material can be further functionalized with different groups to prevent aggregation and extends its potential application. Until today, a plethora of magnetic GO hybrid materials have been synthesized and successfully employed for the magnetic solid-phase extraction of organic compounds from environmental, agricultural, biological, and food samples. The developed GO nanocomposites exhibit satisfactory stability in aqueous solutions, as well as sufficient surface area. Thus, they are considered as an alternative to conventional sorbents by enriching the analytical toolbox for the analysis of trace organic compounds.
\end{abstract}

Keywords: Graphene oxide; magnetic solid-phase extraction; MSPE; organic pollutants; food samples; environmental samples; biological samples; sample preparation

\section{Introduction}

Solid-phase extraction (SPE) and liquid-liquid extraction (LLE) are two widely used and well-established techniques for the extraction of organic compounds. However, these conventional techniques tend to have many fundamental drawbacks such as complicated and time-consuming steps, requirement for a large amount of organic solvents and sample, as well as difficulties in automation [1-4]. Recent trends in sample preparation are focused on the progressive replacement of those techniques by miniaturized and environment-friendly techniques, such as solid-phase microextraction (SPME) [5], dispersive liquid-liquid microextraction (DLLME) [6], fabric phase sorptive extraction (FPSE) [7] and dispersive solid-phase extraction (d-SPE) [8].

Magnetic solid-phase extraction (MSPE) is a form of dispersive solid-phase extraction in which a magnetic sorbent is added into an aqueous sample in order to adsorb the target analytes. The sorbent is easily separated by applying an external magnetic field [9]. Subsequently, the analytes are eluted with the addition of an appropriate solvent and magnetic separation is performed again to collect the liquid phase, which is further analyzed. Compared with traditional SPE procedure, with magnetic 
sorbents there is no need to be packed into SPE cartridges, thus minimizing problems of column blocking and high pressure that are often observed in SPE. Meanwhile, the phase separation with an external magnetic field is a simple and rapid process compared to centrifugation and filtration steps. Sample and organic solvent consumption are also significantly decreased compared to classical SPE and LLE techniques $[9,10]$.

Because of the evolution of technology and nanotechnology, novel extraction sorbents with improved chemical and physical properties have been synthesized and successfully used for magnetic solid-phase extraction of target analytes. Moreover, with the use of these materials, high extraction efficiency, good reproducibility in combination with low detection and quantification limits can be achieved [1,2]. Typical examples of MSPE sorbents are magnetic nanoparticles with surface modification by octadecyl $\left(\mathrm{C}_{18}\right)$ [11], activated carbon [12], carbon-nanotubes [13], graphene [14], graphene oxide [15], metal-organic frameworks [16], covalent organic frameworks [17] and zeolitic imidazole frameworks [18].

Graphene oxide is the oxidized form of graphene that can be easily prepared from natural graphite powder with Hummer's method after reaction with an anhydrous mixture of sulfuric acid, sodium nitrate and potassium permanganate [19-24]. Due to its superior properties such as good thermal and mechanical stability as well as its high surface area, graphene oxide has been used in multiple scientific fields including heterogenous catalysis, gas sorption, storage and separation, sensors and drug delivery [25].

In analytical chemistry, GO has been successfully employed for the sample preparation of a wide variety of samples including biological, food and environmental matrices [26-28]. Graphene oxide consists of one-atom-thick two-dimensional layers of $\mathrm{sp}^{2}$-bonded carbon and the material is rich in oxygen-containing groups including hydroxyl, carboxyl and epoxy groups, which assist the interaction between the sorbent and organic molecules through strong $\pi-\pi$ stacking, hydrophobic interaction and hydrogen bonding [29-31].

Graphene oxide is an ultra-light material that poses high dispersibility in aqueous solutions as well as high hydrophilicity which makes its separation from this kind of solutions difficult. In order to improve the separation, GO can form magnetic nanocomposites with magnetite through electrostatic interaction between the negatively charged graphene oxide sheets and the positively charged surface of $\mathrm{Fe}_{3} \mathrm{O}_{4}$ [32]. The magnetic $\mathrm{GO}$ nanocomposites combine the high adsorption capacity of graphene oxide and the convenience of magnetic separation. Moreover, the hybrid material can be functionalized with different groups to prevent aggregation and extends its application [33,34].

Many reviews have been published regarding the applications of graphene and graphene-based sorbents in the field of the sample preparation [35-39]. Herein we aim to discuss the applications of magnetic graphene oxide derived nanomaterials for the extraction and preconcentration of organic compounds from environmental, agricultural, biological and food samples.

\section{Preparation and Applications of GO for the MSPE of Organic Compounds}

\subsection{Nanocomposites of $\mathrm{GO}$ with $\mathrm{Fe}_{3} \mathrm{O}_{4}$ Nanoparticles}

Due to its high surface area and its superparamagnetic properties $\mathrm{GO} / \mathrm{Fe}_{3} \mathrm{O}_{4}$ has been employed for the extraction of a wide variety of organic compounds from various samples. The surface of magnetic graphene oxide is rich in hydroxyl and carboxyl groups, which assist the interaction between the sorbent and the target analytes through strong $\pi-\pi$ stacking, hydrophobic interaction as well as hydrogen bonding [26-31]. Figure 1 shows the structure of graphite, graphene oxide, reduced graphene oxide, and magnetic graphene oxide. 


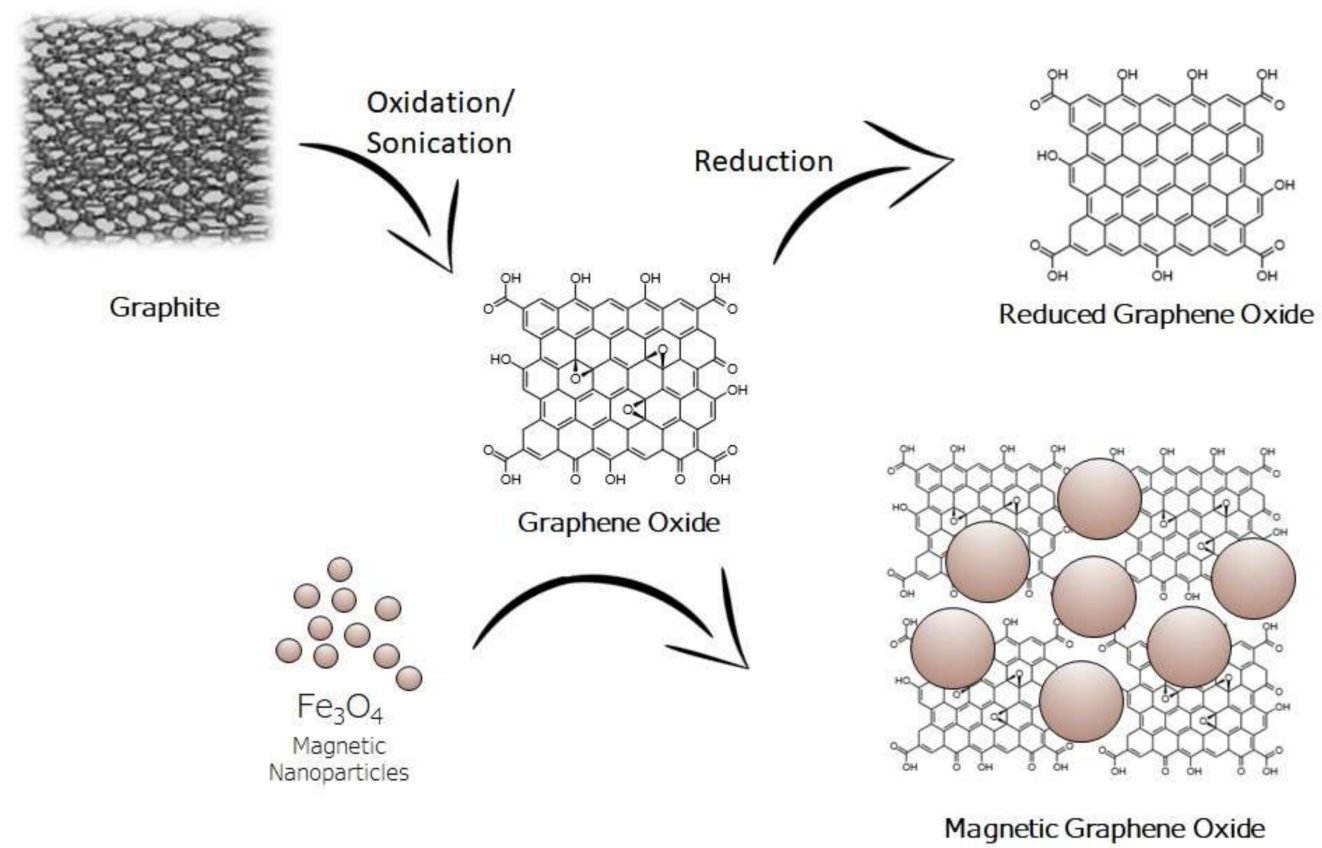

Figure 1. Structure of graphite, graphene oxide, reduced graphene oxide, and magnetic graphene oxide.

The one-step co-precipitation approach is the most common synthetic route for the preparation of magnetic GO. In this approach, graphene oxide is dispersed in water. Subsequently, salts of $\mathrm{Fe}^{2+}$ (e.g., ferrous chloride) and of $\mathrm{Fe}^{3+}$ (e.g., ferric chloride) are added, the mixture is heated and ammonium hydroxide is slowly added and the magnetite nanoparticles are formed [26].

Another common synthetic procedure is the solvothermal approach, in which GO is added in a dispersion of a $\mathrm{Fe}^{3+}$ salt (e.g., ferric chloride hexahydrate) and sodium acetate, under vigorously stirring for $30 \mathrm{~min}$ at room temperature $[33,40]$. The dispersion is transferred in an autoclave and heated under reflux for a specific time span. The ferric salt is added as the iron source, while the sodium acetate assists both the electrostatic stabilization of the magnetic nanoparticles onto GO in order to prevent agglomeration of the particles and the reduction of $\mathrm{Fe}^{3+}$ to $\mathrm{Fe}_{3} \mathrm{O}_{4}$.

Magnetic $\mathrm{GO}$ can be prepared by mixing $\mathrm{GO}$ and $\mathrm{Fe}_{3} \mathrm{O}_{4}$ under ultrasonic irradiation, stirring or mechanical shaking. In this case, $\mathrm{Fe}_{3} \mathrm{O}_{4}$ nanoparticles are dispersed in nitric acid solution in an ultrasonic bath for $30 \mathrm{~min}$ in order to generate a positively charged surface. Graphene oxide is dispersed in deionized water in order to generate a negatively charged surface. Subsequently, the dispersions of $\mathrm{Fe}_{3} \mathrm{O}_{4}$ and $\mathrm{GO}$ are mixed, the $\mathrm{pH}$ of the mixture is adjusted to a desired value and the mixture is subjected to vigorous magnetic stirring, mechanical shaking or ultrasonic radiation for a certain time span (e.g., 5 h) [41]. Finally, the $\mathrm{GO} / \mathrm{Fe}_{3} \mathrm{O}_{4}$ material can be prepared after hydroxylation of $\mathrm{Fe}_{3} \mathrm{O}_{4}$ nanoparticles by mixing with $\mathrm{GO}$ and dimethyl sulfoxide. After ultrasonic treatment of the mixture for a certain time at room temperature, the desired material is obtained [42].

Organic molecules of various chemical groups have been extracted with $\mathrm{GO} / \mathrm{Fe}_{3} \mathrm{O}_{4}$. Table 1 summarizes the applications of $\mathrm{GO} / \mathrm{Fe}_{3} \mathrm{O}_{4}$ for the MSPE of organic compounds from biological, environmental and food samples. 
Table 1. Applications of $\mathrm{GO} / \mathrm{Fe}_{3} \mathrm{O}_{4}$ for the magnetic solid-phase extraction (MSPE) of organic compounds from biological, environmental and food samples.

\begin{tabular}{|c|c|c|c|c|c|c|c|}
\hline Analyte & Sample Matrix & Synthetic Route & Analytical Technique & LODs (ng mL $\left.{ }^{-1}\right)$ & Recovery (\%) & Reusability & Reference \\
\hline \multicolumn{8}{|c|}{ Biological Samples } \\
\hline Tamsulosin hydrochloride & Plasma & Mix/Stirring & HPLC-UV & 0.17 & $98.1-101.4$ & At least 4 times & [43] \\
\hline Pseudoephedrine & Urine & Chemical coprecipitation & HPLC-UV & 25 & 96.42 & N.A. & [44] \\
\hline Psychoactive drugs & Urine & Chemical coprecipitation & UHPLC-MS/MS & $0.02-0.2$ & $80.4-105.5$ & At least 10 times & [45] \\
\hline Methamphetamine & Urine & Chemical coprecipitation & HPLC-UV & 30 & 93.5 & At least 1 time & [46] \\
\hline PAH metabolites & Urine & Mix/Agitation & UHPLC-MS & $0.01-0.15$ & $98.3-125.2$ & N.A. & [47] \\
\hline \multicolumn{8}{|c|}{ Environmental Samples } \\
\hline РCВ 28 & Water & Chemical coprecipitation & GC-MS & $0.027-0.059$ & $77.2-99.7$ & N.A. & [34] \\
\hline Atrazine & Water & Chemical coprecipitation & GC-MS & $0.6 \times 10^{-3}$ & $96-102$ & N.A. & [48] \\
\hline DEHP & Water & Solvothermal approach & HPLC-DAD & 0.35 & $91.6-106.5$ & N.A. & [49] \\
\hline PAHs & Water & Chemical coprecipitation & HPLC-UV & $0.09-0.19$ & $76.8-101.2$ & N.A. & [32] \\
\hline TNT & Water & Mix/Stirring & HPLC-UV & 0.3 & $87-120$ & Up to 6 times & [41] \\
\hline $\begin{array}{l}\text { Malachite Green, } \\
\text { Crystal Violet }\end{array}$ & Water & Chemical coprecipitation & HPLC-UV & $0.091-0.12$ & $91.5-116$ & N.A. & [50] \\
\hline Imatinib, doxorubicin & Water & Mix/Stirring & HPLC-UV & $1.8-1.9$ & $88.4-96.7$ & N.A. & [51] \\
\hline Sulfonamides & Water & Chemical coprecipitation & HPLC-DAD & $50-100$ & $67.4-119.9$ & N.A. & [52] \\
\hline \multicolumn{8}{|c|}{ Food Samples } \\
\hline Sulfonamides & Milk & Chemical coprecipitation & HPLC-MS/MS & $0.02-0.13$ & $73.4-97.4$ & At least 6 times & [53] \\
\hline Sulfonamides & Milk & Solvothermal approach & CE-DAD & $0.89-2.31$ & $62.7-104.8$ & At least 3 times & [54] \\
\hline Sulfadiazine & Milk, honey, water & Chemical coprecipitation & Spectrophotometry & 340 & $94.3-100.7$ & At least 10 times & [55] \\
\hline Patulin & Apple juice & Chemical coprecipitation & HPLC-UV & $2.3 \mathrm{ng} \mathrm{g}^{-1}$ & $68.7-83.6$ & At least 10 times & [56] \\
\hline Flavors, fragrances & $\begin{array}{c}\text { Orange juice, } \\
\text { chocolate, fruit sugar }\end{array}$ & Chemical coprecipitation & HPLC-DAD & $20-40$ & $71.5-112.4$ & At least 5 times & [57] \\
\hline Flavonoids & Tea, wine, urine & Solvothermal approach & HPLC-DAD & $0.2-6.0$ & $82.0-101.4$ & N.A. & [33] \\
\hline Azo dyes & Jelly, candy, plum & Solvothermal approach & HPLC-UV & $0.36-2.23 \mathrm{ng} \mathrm{g}^{-1}$ & $73.2-107.7$ & Up to 6 times & [40] \\
\hline Lignans & Sesame oil & Hydroxylation, sonication & HPLC-UV & $20-50 \mathrm{ng} \mathrm{g}^{-1}$ & $84.6-86.8$ & N.A. & [42] \\
\hline
\end{tabular}


Regarding the analysis of biological samples, graphene oxide has been employed for the MSPE of tamsulosin hydrochloride [43], pseudoephedrine [44], psychoactive drugs (including morphine, 6-monoacetylmorphine, amphetamine, methamphetamine, codeine, cocaine, dolantin and benzoylecgonine) [45], methamphetamine [46], flavonoids [33], as well as monohydroxy polycyclic aromatic hydrocarbons [47]. High-performance liquid chromatography (HPLC) with ultraviolet detector (UV), diode array detector (DAD), mass spectrometer (MS), or tandem mass spectrometer (MS/MS) have been employed for the separation and determination of the target analytes. The MSPE methods provide good extraction recoveries $(>80 \%)$ and low limit of detections (LODs). Since the adsorbents provided nearly quantitative extraction recoveries in most cases, it can be concluded that the differences of the LOD values for the same compounds in similar sample matrices, mainly depend on the detection technique (e.g., $\mathrm{DAD}, \mathrm{MS}$, tandem MS, etc.). Moreover, the $\mathrm{GO} / \mathrm{Fe}_{3} \mathrm{O}_{4}$ material was found to be reusable in most cases.

The $\mathrm{GO} / \mathrm{Fe}_{3} \mathrm{O}_{4}$ magnetic nanocomposite has been employed for the extraction of 2,4,4' -trichlorobiphenyl (PCB 28) [34] and atrazine [48] from water samples prior to their determination by gas chromatography-mass spectrometry (GC-MS). Furthermore, di-2-ethylhexyl phthalate (DEHP) [49], polycyclic aromatic hydrocarbons (PAHs) [32], 2,4,6-trinitrotoluene (TNT) [41], malachite green and crystal violet [50], the cytostatic drugs imatinib and doxorubicin [51] as well as sulfonamides [52] have been extracted from water samples prior to their separation with HPLC and determination using a UV or DAD detector. Figure 2 shows the transmission electron microscopy (TEM) image, (a), a Fourier-Transformation Infrared spectroscopy (FT-IR) image (b), an X-ray diffraction (XRD) image (c) and a vibrating sample magnetometer (VSM) image (d) of $\mathrm{GO} / \mathrm{Fe}_{3} \mathrm{O}_{4}$.
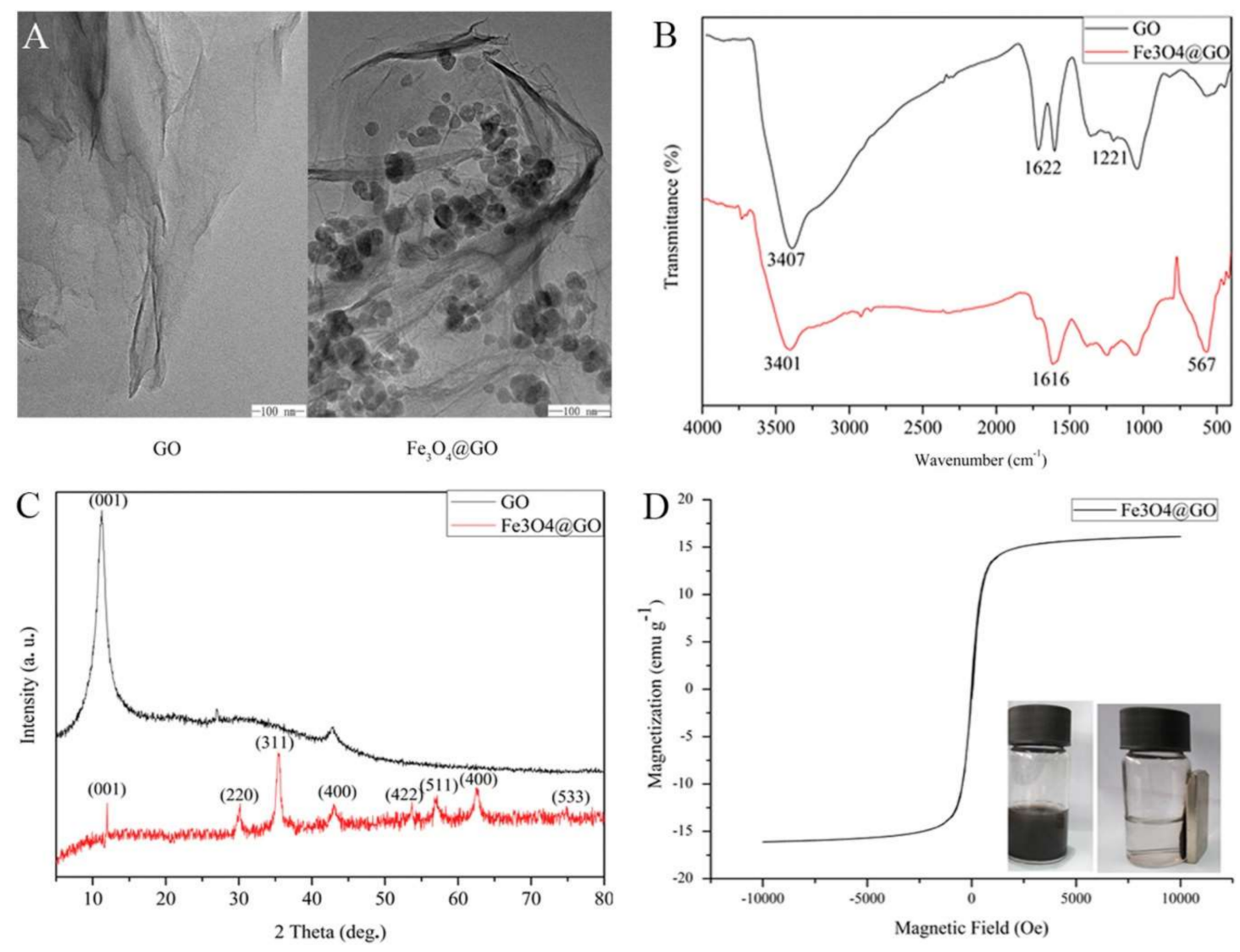

Figure 2. TEM (a), FT-IR (b), XRD (c) and vibrating sample magnetometer (VSM) (d) of $\mathrm{GO} / \mathrm{Fe}_{3} \mathrm{O}_{4}$. Reproduced with permission from [57]. Copyright Elsevier, 2017. 
Sulfonamides have been extracted from milk samples by $\mathrm{GO} / \mathrm{Fe}_{3} \mathrm{O}_{4}$ sorbent prior to their determination by HPLC-MS/MS [53] or capillary electrophoresis-diode array detection (CE-DAD) [54]. Sulfadiazine has been extracted from milk, honey and water samples with $\mathrm{GO} / \mathrm{Fe}_{3} \mathrm{O}_{4}$ prior to its spectrophotometric and optimized angle mode-mismatched thermal lens spectrometric determination (OAMTLS) [55].

Other applications of $\mathrm{GO} / \mathrm{Fe}_{3} \mathrm{O}_{4}$ for the extraction of organic compounds from food samples include the extraction of patulin from apple juice [56], flavors and fragrances (including ethyl vanillin, trans-cinnamic acid, methyl cinnamate, ethyl cinnamate, and benzyl cinnamate) from orange juice, chocolate and fruit sugar [57], lignans from sesame oil [42], flavonoids from tea, wine and urine samples [33], azo dyes (tartrazine, amaranth, carmine, sunset yellow, allura red) from jellies and candies [40].

The organic solvents that were mainly used for the elution of the adsorbed analytes from the $\mathrm{GO} / \mathrm{Fe}_{3} \mathrm{O}_{4}$ nanomaterial include acetone, n-hexane, acetonitrile, methanol etc., however, only a small quantity of these solvents was required. In most cases, the $\mathrm{GO} / \mathrm{Fe}_{3} \mathrm{O}_{4}$ sorbent was found to be reusable after a regeneration and a washing step. The as-prepared nanomaterial has some significant benefits including high surface area, superparamagnetic properties and strong magnetism. The synthetic procedures that were reported were simple, mild, rapid an economic and the MSPE method provided the benefits of limited organic waste, no requirement for time-consuming centrifugation, column-passing or filtration steps.

\subsection{Nanocomposites of Reduced $\mathrm{GO}$ with $\mathrm{Fe}_{3} \mathrm{O}_{4}$ Nanoparticles}

Reduced graphene oxide (RGO) is a nanomaterial obtained by chemical reduction of graphene oxide that contains less oxygen groups and has properties closer to those of graphene $[25,58]$. RGO has various applications such as removal of metals and dyes [59,60], catalysts [61], electroanalytical sensors [62] etc. Magnetic nanocomposites of reduced graphene oxide have been successfully applied for the MSPE of various analytes from different sample matrices. Due to the combination of the magnetic $\mathrm{Fe}_{3} \mathrm{O}_{4}$ nanoparticles and the graphene sheets, the magnetic RGO sorbent shows distinguished properties including good dispersity, high surface area, high adsorption efficiency and good super-paramagnetism [63].

There are different synthetic procedures for the fabrication of $\mathrm{RGO} / \mathrm{Fe}_{3} \mathrm{O}_{4}$ sorbents. The co-precipitation approach is a multi-step procedure in which $\mathrm{GO} / \mathrm{Fe}_{3} \mathrm{O}_{4}$ previously prepared by precipitating $\mathrm{Fe}^{2+}$ and $\mathrm{Fe}^{3+}$ in the presence of $\mathrm{GO}$ is reduced with the addition of hydrazine hydrate [64,65]. For the solvothermal approach, graphite oxide is exfoliated in diethylene glycol under sonication to produce graphene oxide while ferric chloride with sodium acetate are also dissolved in diethylene glycol. In this case, diethylene glycol was both solvent and reducing agent. Accordingly, the GO dispersion is added into the second solution and the mixture was sonicated and heated at $190^{\circ} \mathrm{C}$ in an autoclave $[64,66]$. The $\mathrm{RGO} / \mathrm{Fe}_{3} \mathrm{O}_{4}$ can be also prepared through the hydrothermal method, which is similar to the solvothermal but instead of organic solvents that are used in the solvothermal method, water is used as a solvent in the hydrothermal approach. For this purpose, a salt of $\mathrm{Fe}^{3+}$ and sodium hydroxide is added to an aqueous solution of graphene oxide and the mixture is heated in an autoclave for a certain time span $[64,67]$. Figure 3 shows the scanning electron micrographs (SEM) of $\mathrm{RGO} / \mathrm{Fe}_{3} \mathrm{O}_{4}$ prepared by solvothermal $(a)$, hydrothermal $(b)$ and co-precipitation $(c)$ methods. 

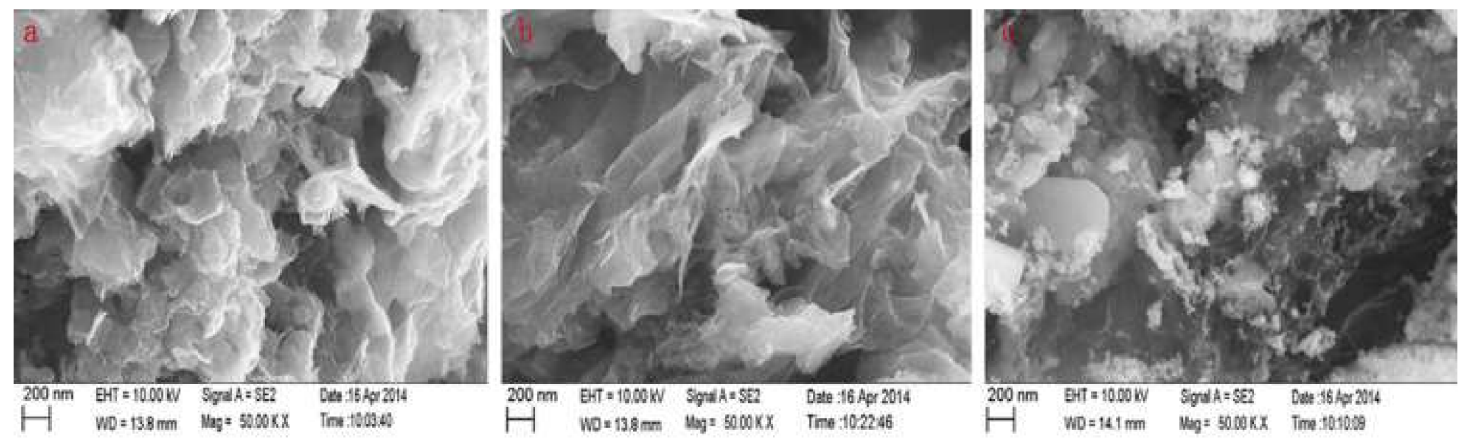

Figure 3. Scanning electron micrographs of reduced graphene oxide ( $\mathrm{RGO}) / \mathrm{Fe}_{3} \mathrm{O}_{4}$ prepared by solvothermal (a), hydrothermal (b) and co-precipitation (c) methods. Reproduced with permission from [64]. Copyright Elsevier, 2015.

Sudan dyes have been extracted from tomato sauce and chili-containing foods with $\mathrm{RGO} / \mathrm{Fe}_{3} \mathrm{O}_{4}$ prior to their determination by HPLC-DAD [68]. The developed MSPE procedure was simple, economic and provided satisfactory extraction recoveries and LOD values. Magnetic $\mathrm{RGO} / \mathrm{Fe}_{3} \mathrm{O}_{4}$ has been also used for the MSPE of bisphenol A from water samples prior to its determination by HPLC-UV. The MSPE technique was coupled with dispersive liquid-liquid microextraction (DLLME) in order to utilize the benefits of both sample preparation techniques. The magnetic sorbent was separated conveniently and rapidly from the sample matrix and it was found to be reusable for at least 12 repeated cycles [69].

In 2016, Mehdinia et al. developed a microwave-assisted synthesis of reduced graphene oxide decorated with magnetite and gold nanoparticles. Gold nanoparticles offer the benefits of chemical stability, biocompatibility, satisfactory magnetic properties and possibility for chemical modification. The $\mathrm{RGO} / \mathrm{Fe}_{3} \mathrm{O}_{4} @ \mathrm{Au}$ sorbent was used for the MSPE of organochlorine pesticides from seawater samples prior to their determination with GC-MS [70].

A magnetic polyethyleneimine functionalized reduced graphene oxide nanocomposite was synthesized and used for the MSPE of polar non-steroidal anti-inflammatory drugs from water samples [71] and polar acidic herbicides from rice [72]. The modification of RGO with polyethyleneimine changed the polarity of RGO to some extent and offered more active sites for the adsorption of the polar target analytes.

In 2018, Feng et al. synthesized $\mathrm{RGO} / \mathrm{Fe}_{3} \mathrm{O}_{4}$-carbon nanotubes composite via a simple and green one-pot solvothermal approach. For this purpose, iron (III) chloride hexahydrate, sodium acetate, GO and CNTs were added in a Teflon-liner and the suspension was heated at $200{ }^{\circ} \mathrm{C}$ for $10 \mathrm{~h}$. It was found that the $\mathrm{Fe}_{3} \mathrm{O}_{4}$ nanoparticles were covered with RGO and CNTs, while CNTs were inserted between the RGO sheets in order to prevent the aggregation of the RGO sheets. The novel sorbent was used for the MSPE of sulfonamides from milk prior to their determination with HPLC-UV [73]. Pinsrithong and Bunkoed prepared a hierarchical porous polypyrrole-coated nanostructured composite of RGO and $\mathrm{Fe}_{3} \mathrm{O}_{4}$ nanoparticles. After incorporation into alginate hydrogel microspheres, the developed sorbent was successfully applied for the MSPE of phthalates from bottled drinks [74].

In order to increase the selectivity of the conventional $\mathrm{RGO} / \mathrm{Fe}_{3} \mathrm{O}_{4}$ sorbent, Mahpishanian and Sereshti reported the one-step green synthesis of $\beta$-cyclodextrin/iron oxide-RGO nanocomposite. The sorbent was used for the MSPE organochlorine pesticides residue from honey samples prior to their determination by gas chromatography-electron capture detection (GC-ECD). In this case, functionalization with $\beta$-cyclodextrin was chosen, due to the high potential supramolecular recognition capability of $\beta$-cyclodextrin [75].

Akbarzade et al. synthesized zero valent Fe-RGO quantum dots and used them for the MSPE of organophosphorus pesticides from real water and fruit juice samples prior to their determination with GC-MS. The quantum dots were prepared with a hydrothermal cutting method and sodium borohydride was used for the reduction. The novel sorbent provided short extraction time, simple operation as well as high enhancement factor [76]. 


\subsection{Functionalized Nanocomposites of $\mathrm{GO}$ with $\mathrm{Fe}_{3} \mathrm{O}_{4}$ Nanoparticles}

The main disadvantage of graphene oxide-based adsorbents is the important $\pi-\pi$ stacking interactions between graphene oxide nanosheets, which are responsible for serious aggregation and restacking of the nanosheets, resulting in a potential block of the active adsorption sites of the sorbent and a decrease of its specific surface area. In order to overcome this problem, functionalization of the sorbent with different molecules that can enter between the GO nanosheet and prevent them from aggregation and restacking can take place [77].

In order to overcome this limitation, Yilmaz et al. developed a magnetic nanodiamond/graphene oxide hybrid and used it for the MSPE of sildenafil from alleged herbal aphrodisiacs by HPLC-DAD system. Functionalization with nanodiamond successfully prevented the aggregation and restacking of GO nanosheets [77].

Functionalization of graphene oxide-based adsorbents can also take place to enhance the extraction efficiency of the material by introducing compatible chemical molecules with high surface area and abundant functional groups in the structure of GO.

Polyamidoamine (PAMAM) dendrimer has been used to develop amino-terminated hyper-branched PAMAM polymer grafted magnetic graphene oxide nanosheets for the MSPE of selective serotonin reuptake inhibitors from plasma samples [78]. Due to the large number of terminal groups of polyamidoamine dendrimer, the structural characteristics as well as the internal spaces between their branches, which can trap the target analyte, the functionalized $\mathrm{GO} / \mathrm{Fe}_{3} \mathrm{O}_{4}$ sorbent exhibited higher extraction efficiency compared to the conventional $\mathrm{GO} / \mathrm{Fe}_{3} \mathrm{O}_{4}$ nanocomposite.

Functionalization with soluble eggshell membrane protein (SEP) was found to increase the stability and adsorption performance as well as accuracy and recoveries of $\mathrm{GO} / \mathrm{Fe}_{3} \mathrm{O}_{4}$ due to the high density of surface functional groups such as amines, amides and carboxylic groups of SEP [79].

Porphyrin has been also used for the functionalization of $\mathrm{GO} / \mathrm{Fe}_{3} \mathrm{O}_{4}$ nanocomposite and the sorbent was used for the MSPE of sulfonamides from tap and river water samples [80]. Due to the $\pi-\pi$ stacking and electrostatic attraction between the negatively charged functionalized nanocomposite and the positively charged sulfonamides, the extraction process was accelerated. The novel sorbent showed higher adsorption capacity than the conventional $\mathrm{GO} / \mathrm{Fe}_{3} \mathrm{O}_{4}$.

A co-polymer of divinylbenzene (DVB) and glycidylmethacrylate (GMA) was used for the functionalization of $\mathrm{GO} / \mathrm{Fe}_{3} \mathrm{O}_{4}$ in order to develop a sorbent for the MSPE of chlorophenols from environmental water prior to their determination by HPLC-MS/MS [81]. Due to $\pi-\pi$ stacking and hydrogen-bonding interactions between the analytes and the functionalized adsorbent, good extraction efficiency was observed.

Polystyrene (PS) [82] and poly(pyrrole-co-aniline) [83] are two examples of functional groups that were employed to prepare magnetic graphene functionalized nanocomposites, which were used for the MSPE of PAHs from water samples. Polystyrene is rich in phenyl and alkyl groups. Therefore, functionalization with PS enhanced the extraction efficiency by increasing the active surface sites of the material. The sorbent exhibited sufficient surface area, excellent magnetic properties and resulted in good extraction efficiencies and low detection limits [82]. Similarly, the poly(pyrrole-co-aniline) functionalized graphene oxide nanocomposite combined the properties of the polypyrrole and polyaniline co-polymer, the GO, and the magnetic nanoparticles. As a result, the developed nanocomposite exhibited a significant enhancement of extraction efficiency due to the increased number of active surface sites on the sorbent as well as the protection of the $\mathrm{Fe}_{3} \mathrm{O}_{4}$ nanoparticles [83].

Polythionine was also employed for the functionalization of magnetic graphene oxide through an oxidative polymerization reaction of thionine on the surface of $\mathrm{GO} / \mathrm{Fe}_{3} \mathrm{O}_{4}[84,85]$. This surface modification significantly improved the merits of $\mathrm{GO} / \mathrm{Fe}_{3} \mathrm{O}_{4}$, providing satisfactory extraction efficiency. The functionalized nanocomposite was used for the MSPE of chlorpheniramine [84] and duloxetine [85] from human plasma prior to their determination by HPLC-UV. 
In order to enhance the dispersibility of magnetic GO in hydrophobic media, functionalization with phytic acid has been reported. Phytic acid-stabilized $\mathrm{GO} / \mathrm{Fe}_{3} \mathrm{O}_{4}$ was applied for extraction of PAHs from vegetable oils. Due to the super-amphiphilicity of phytic acid, the dispersibility of the conventional $\mathrm{GO} / \mathrm{Fe}_{3} \mathrm{O}_{4}$ sorbent increased. [86].

Functionalization of $\mathrm{GO} / \mathrm{Fe}_{3} \mathrm{O}_{4}$ can also be performed for the enhancement of its selectivity towards the target analytes. In 2015, Abdolmohammad-Zadeh and Talleb synthesized a $\beta$-cyclodextrin $(\beta-C D)$ grafted $\mathrm{GO} / \mathrm{Fe}_{3} \mathrm{O}_{4}$ nano-hybrid and used it for the MSPE of gemfibrozil from human serum and pharmaceutical waste-water samples followed by determination using spectrofluorometry. This chemical compound can selectively bind with various organic, inorganic and biological guest molecules into its cavity to form stable host-guest inclusion complexes by a series of forces such as hydrophobic and van der Waals interactions. Therefore, due to the surface modification of graphene oxide with $\beta$-cyclodextrin, selective separation of the target analyte from complex sample matrices was achieved [87].

Other examples of chemical molecules that have been used for the functionalization of $\mathrm{GO} / \mathrm{Fe}_{3} \mathrm{O}_{4}$ are triethylenetetramine [88], silica [89], sporopollenin [90] and phenylethyl amine [91]. The superior adsorption capacity of the functional groups resulted in functionalized magnetic GO nanocomposites with sufficient surface area, excellent extraction efficiency, good stability as well as ease in handling and separation. Table 2 summarizes the application of functionalized $\mathrm{GO} / \mathrm{Fe}_{3} \mathrm{O}_{4}$ nanocomposites. 
Table 2. Application of functionalized $\mathrm{GO} / \mathrm{Fe}_{3} \mathrm{O}_{4}$ nanocomposites for the MSPE of organic compounds.

\begin{tabular}{|c|c|c|c|c|c|c|c|}
\hline Analyte & Sample Matrix & Functional Group & Analytical Technique & LODs (ng mL $\left.L^{-1}\right)$ & Recovery (\%) & Reusability & Reference \\
\hline \multicolumn{8}{|c|}{ Biological Samples } \\
\hline Chlorpheniramine & Plasma & Polythionine & HPLC-UV & 0.4 & $87.9-96.4$ & At least 6 times & [84] \\
\hline Duloxetine & Plasma & Polythionine & HPLC-UV & 0.5 & 87 & At least 9 times & [85] \\
\hline Gemfibrozil & Serum & $\beta-C D$ & Spectrofluorometry & $3 \times 10^{-3}$ & $96.0-104.0$ & At least 50 times & [87] \\
\hline SSRIs & Plasma & PAMAM & HPLC-UV & $0.3-0.9$ & 89.1-97.9 & Up to 20 times & [78] \\
\hline \multicolumn{8}{|c|}{ Environmental Samples } \\
\hline Sulphonamide & Water & Porphyrin & HPLC-DAD & 200 & $83.7-116.7$ & At least 8 times & [80] \\
\hline Chlorophenols & Water & $\begin{array}{c}\text { Poly } \\
\text { (DVB-co-GMA) }\end{array}$ & HPLC-MS/MS & $0.6-9.2$ & $86.4-99.8$ & N.A. & [81] \\
\hline PAHs & Water & Polystyrene & GC-FID & $3 \times 10^{-3}-10 \times 10^{-3}$ & $69.5-88.7$ & N.A. & [82] \\
\hline PAHs & Water & Poly(pyrrole-co-aniline) & GC-FID & $0.003-0.01$ & $50.4-78.3$ & At least 20 times & [83] \\
\hline Estrogens & Water & Triethylenetetramine & LC-MS/MS & $0.15-1.5 \times 10^{-3}$ & $88.5-105.6$ & N.A. & [88] \\
\hline Malachite green & Water & SEP & UV Vis & 0.2 & 96.3 & At least 50 times & [79] \\
\hline \multicolumn{8}{|c|}{ Food Samples } \\
\hline $\begin{array}{l}\text { Organophosphorus } \\
\text { pesticides }\end{array}$ & Vegetables & Sporopollenin & GC-ECD & $0.02-0.05$ & $81.0-120.0$ & N.A. & [90] \\
\hline $\begin{array}{l}\text { Organophosphorus } \\
\text { pesticides }\end{array}$ & $\begin{array}{l}\text { Fruit, vegetables, } \\
\text { water }\end{array}$ & Phenylethyl amine & GC-NPD & $0.02-0.1$ & $>80.4$ & At least 30 times & [91] \\
\hline PAHs & Vegetable oils & Phytic acid & HPLC-DAD & $0.06-0.15 \mathrm{ng} \mathrm{g}^{-1}$ & $85.6-102.3$ & At least 20 time & [86] \\
\hline sildenafil citrate & $\begin{array}{l}\text { Herbal supplementary } \\
\text { products }\end{array}$ & Nanodiamond & HPLC-DAD & 1.49 & $94.0-104.1$ & At least 10 times & [77] \\
\hline \multicolumn{8}{|c|}{ Agricultural Samples } \\
\hline Cytokinins & Plants & Silica & HPLC-MS/MS & $93-120 \times 10^{3}$ & 78.9-97.3 & At least 30 times & [89] \\
\hline
\end{tabular}


Moreover, Figure 4 summarizes the synthesis of phenylethyl amine functionalized $\mathrm{GO} / \mathrm{Fe}_{3} \mathrm{O}_{4}$ and its application in the MSPE procedure.
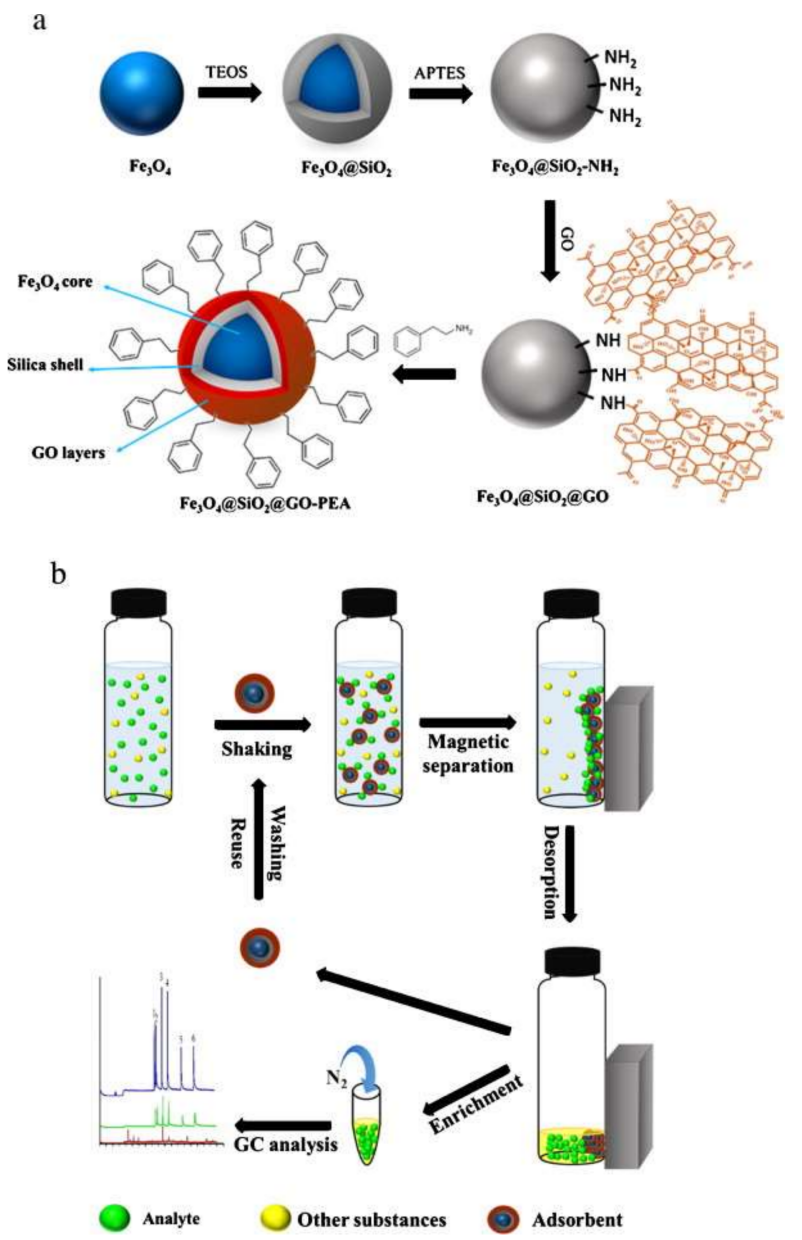

Figure 4. Synthesis of phenylethyl amine functionalized $\mathrm{GO} / \mathrm{Fe}_{3} \mathrm{O}_{4}(\mathbf{a})$ and its application on the MSPE procedure (b). Reproduced with permission from [91]. Copyright Elsevier, 2015.

\subsection{Functionalized Nanocomposites of Magnetic GO with MIPs}

Molecularly imprinted polymers (MIPs) are highly selective, tailor-made synthetic polymeric materials that exhibit high adsorption capacity. Moreover, they can be easily prepared with economic synthetic procedures. Therefore, MIPs have been applied for the extraction and preconcentration of trace analytes in diverse fields, including natural, agricultural, and food products and environmental samples [92-94]. The combination of graphene oxide and molecularly imprinted polymers can significantly enhance the selectivity of the extraction procedure [93,94].

Ning et al. developed a molecularly imprinted polymer on magnetic GO and used it for the extraction of $17 \beta$-estradiol from milk powder samples. For this purpose, $\mathrm{GO} / \mathrm{Fe}_{3} \mathrm{O}_{4}$ nanoparticles were grafted with acrylic acid. Subsequently, the MIPs-GO/Fe $\mathrm{O}_{4}$ sorbent was prepared from $17 \beta$-E2 (template molecule), acrylamide (functional monomer), ethylene glycol dimethacrylate (cross-linker), and 2,2'-azobis(isobutyronitrile) (initiator) in acetonitrile dispersion of the functionalized magnetic GO material. With the use of developed sorbent, specific recognition, as well as highly effective removal of $17 \beta-E 2$ from complicated matrices, were achieved [95]. Barati et al. synthesized a molecular imprinted polymer based on magnetic chitosan/graphene oxide and used it for the selective extraction of fluoxetine from environmental and biological samples prior to its spectrophotometric determination. Due to the multi imprinting sites and high surface area of the magnetic chitosan/GO, high selectivity and adsorption efficiency was observed [96]. 


\subsection{Functionalized Nanocomposites of Magnetic GO with MOFs}

Metal-organic frameworks are mixed organic-inorganic supramolecular materials that became popular in 1995, when Yaghi and Li reported the synthesis of a MOF with large rectangular channels [97]. These materials are based on the coordination of metal ions or clusters with bi- or multidentate organic linkers [98,99]. Metal-organic frameworks exhibit various extraordinary properties including luminosity, tunable pore size, flexibility and thermal stability as well as high surface areas [100,101].

The combination of graphene oxide and metal organic frameworks enhances the merits of sorbent including its reusability, its pore volume, its dispersion capability, its extraction capacity, its mechanical strength as well as its surface area [102-104].

Liu et al. developed a sorbent based on magnetic graphene oxide functionalized MOF-199 with the aim to combine the benefits of $\mathrm{GO} / \mathrm{Fe}_{3} \mathrm{O}_{4}$ and $\mathrm{MOF}$ for the rapid separation and highly selective adsorption of triazole pesticides [105]. The sorbent was employed for the MSPE of triazole pesticides from environmental water samples prior to their determination by HPLC-MS/MS. High adsorption capacity for the target analytes was observed due to the high surface area and pore volume of the novel nanocomposite.

A high-affinity graphene oxide-encapsulated magnetic zirconium-MOF was developed for the MSPE of photosensitizers hematoporphyrin and hematoporphyrin monomethyl ether from human urine prior to their determination by ultra-performance liquid chromatography-high resolution mass spectrometry (UPLC-HRMS) [106]. The novel sorbent combined the advantages of GO, magnetic nanoparticles with the advantages of large surface area, high porosity, and easy modification of metal-organic frameworks.

Wang et al. synthesized magnetic Cu-MOFs embedded within graphene oxide nanocomposites and used it for the MSPE of benzenoid-containing insecticides prior to their determination by HPLC-UV [107]. For this purpose, GO nanosheets were functionalized with silica-coated $\mathrm{Fe}_{3} \mathrm{O}_{4}$ nanoparticles with core-shell structured through covalent bonding and subsequently the GO surfaces were modified with $\mathrm{Cu}-\mathrm{MOF}$. The silica shells prevented the oxidation and agglomeration of $\mathrm{Fe}_{3} \mathrm{O}_{4}$ nanoparticles and served as a platform to integrate the $\mathrm{Fe}_{3} \mathrm{O}_{4}$ particles and $\mathrm{GO}$ nanosheets through covalent bonds. Finally, the functionalization with the $\mathrm{Cu}-\mathrm{MOF}$ enhanced the extraction efficiency by providing more active sites for adsorption because of the high porosity and tunability of MOFs. Figure 5 shows the SEM images of TEM Cu-MOFs (a) and $\mathrm{Fe}_{3} \mathrm{O}_{4} @ \mathrm{SiO}_{2}-\mathrm{GO}-\mathrm{MOFs}(\mathrm{b})$ as well as the TEM Cu-MOFs (c) and $\mathrm{Fe}_{3} \mathrm{O}_{4} @ \mathrm{SiO}_{2}-\mathrm{GO}-\mathrm{MOFs}(\mathrm{d})$.

Pourbahman et al. synthesized a graphene oxide/metal-organic framework-74/ $\mathrm{Fe}_{3} \mathrm{O}_{4} /$ polytyramine (GO/MOF-74/ $\mathrm{Fe}_{3} \mathrm{O}_{4} / \mathrm{PTy}$ ) nanoporous composite and used it for the magnetic dispersive micro solid-phase extraction (MD- $\mu$-SPE) of prokinetic drugs prior to their determination with HPLC-UV [102]. The surface modifiers were employed to improve the properties of graphene oxide, including the surface area-to-volume ratio, the adsorption capacity as well as its selectivity. Other nanocomposites of GO and metal-organic frameworks were reported by the working group of Cao [103] and the working group of Zhang [104]. The first group synthesized a magnetic zeolitic imidazolate framework (ZIF) 67/graphene oxide composite material and used it for the MSPE of neonicotinoid insecticides from environmental water samples [103]. The combination of the ZIF and GO nanoparticles was performed to facilitate enhancement of the sorbent properties. The second group synthesized a magnetic zeolitic imidazolate framework-7 supported graphene oxide nanocomposite with the assistance of polydopamine and used it for the MSPE of fungicides from environmental water and soil samples. It was found that the combination of ZIF units and GO layers synergistically enhanced the extraction of fungicides [104]. However, in both cases, no information on sorbent reusability was provided. 

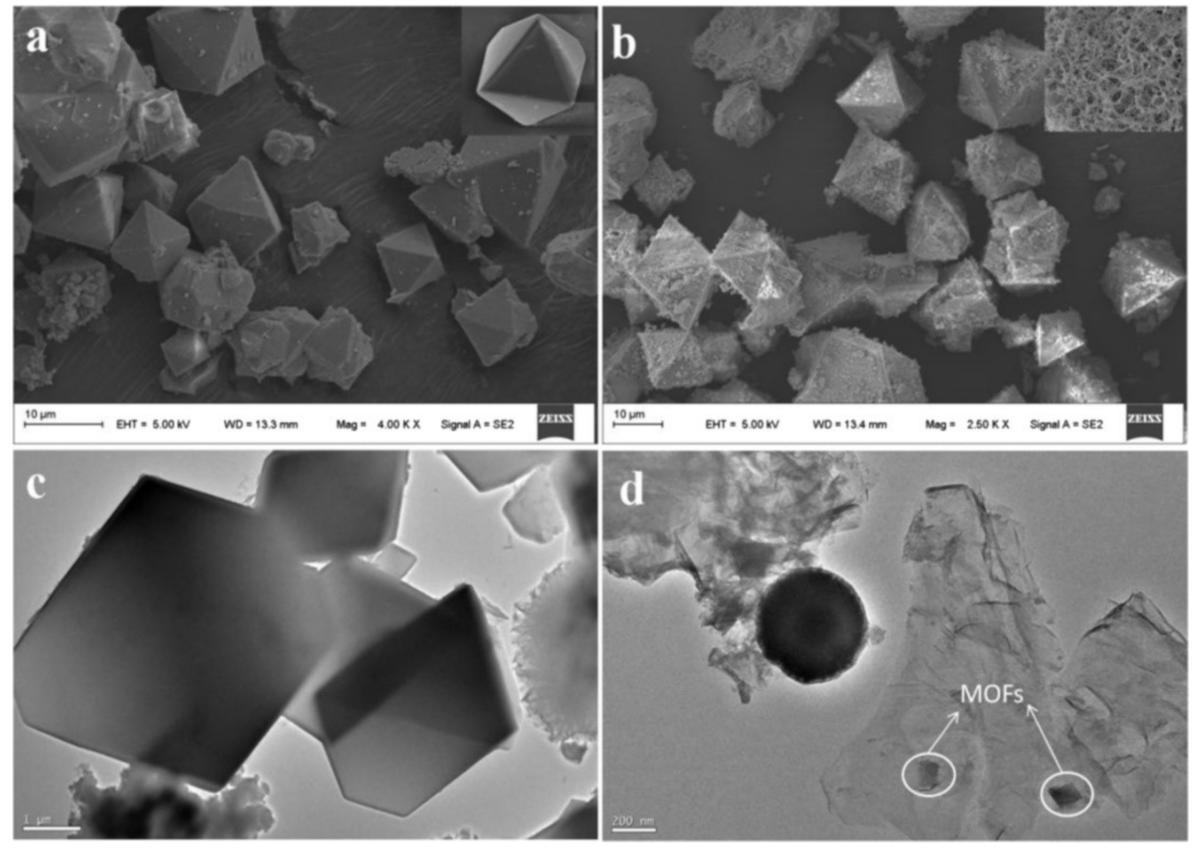

Figure 5. SEM images of $\mathrm{Cu}-\mathrm{MOFs}(\mathbf{a})$ and $\mathrm{Fe}_{3} \mathrm{O}_{4} @ \mathrm{SiO}_{2}-\mathrm{GO}-\mathrm{MOFs}(\mathbf{b})$ and TEM images of $\mathrm{Cu}-\mathrm{MOFs}$ (c) and $\mathrm{Fe}_{3} \mathrm{O}_{4} @ \mathrm{SiO}_{2}-\mathrm{GO}-\mathrm{MOFs}$ (d). Reproduced with permission from [107]. Copyright Elsevier, 2018.

\subsection{Functionalized Nanocomposites of Magnetic GO with MOPs}

Microporous organic polymers (MOPs) represent a class of amorphous porous materials, composed of fully covalently bound organic building blocks. MOPs have lately gained much research interest, due to the combined superiority of porous materials and functional polymers [108-110]. MOPs exhibit well-defined porosity as well as high surface area. Because of their tunable surface chemistry, MOPs can be easily functionalized [108]. Depending on the choice of monomers, functionality and polymerization method, MOPs can be prepared both as solution processable or as insoluble networked materials [109]. Therefore, MOPs have various applications including gas storage [111], environmental remediation [112], catalysis [113], energy storage [114] etc. In analytical chemistry, MOPs have been used as sorbents for the extraction of different organic compounds including hydroxylated PAHs [115] and 5-nitroimidazoles [116].

By combining MOPs and magnetic GO it is possible to develop nanocomposites that combine the extraordinary properties of both MOPs and GO. Shahrebabak et al. synthesized a triazine-based polymeric network modified magnetic nanoparticles/GO nanocomposite and used it for the MSPE of basic and acidic pesticides from food (e.g., cucumber, tomato) and water samples by HPLC-UV. For the fabrication of the material, $\mathrm{Fe}_{3} \mathrm{O}_{4}$ nanopaticles were modified by triazine-based polymeric prepared from melamine and terephthaldehyde. Subsequently, the functionalized $\mathrm{Fe}_{3} \mathrm{O}_{4}$ nanoparticles were mixed with GO in THF and the mixture was sonicated. The novel sorbent showed well-defined porosity, high surface area, good chemical stability and tunable surface chemistry. Due to the different functional groups of the nanocomposite (i.e., amine and carboxylic groups), simultaneous extraction of basic and acidic pesticides was achieved [108].

\subsection{Applications of Magnetic GO Nanocomposites Modified with Ionic Liquids (ILs) and Deep Eutectic Solvents (DESs)}

Ionic liquids (ILs) and deep eutectic solvents (DESs) are an alternative to environmentally harmful ordinary organic solvents. ILs are generally composed of bulky, non-symmetrical organic cations (i.e., imidazolium, ammonium pyrrolidinium, pyridinium etc.) and different inorganic or organic anions [117-119]. DESs are systems formed from a eutectic mixture of Lewis or Brønsted acids and bases that contain a variety of anionic and/or cationic species [120,121]. ILs and DESs have 
a tunable nature and their properties can be optimized through the choice of their cationic and anionic constituents [118,119]. Although DESs and ILs have similar physical properties, their chemical properties differ resulting in different potential applications [122,123]. By combining ionic liquids and deep eutectic sorbents with magnetic graphene oxide it is possible to design and develop new extraction sorbents with extraordinary properties [117,123].

In 2016, Cai et al. synthesized a planar graphene oxide-based magnetic ionic liquid nanomaterial for extraction of chlorophenols from environmental water samples coupled with HPLC-MS/MS [123]. For this purpose, $\mathrm{Fe}_{3} \mathrm{O}_{4} @ \mathrm{SiO}_{2}$ magnetite microspheres functionalized with amino-groups $\left(\mathrm{Fe}_{3} \mathrm{O}_{4}\right.$ $@ \mathrm{SiO}_{2}-\mathrm{NH}_{2}$ ) and 1-carboxymethyl-3-methylimidazolium chloride were used to functionalize graphene oxide. The novel sorbent exhibited great adsorption capacity and was successfully used to extract both polar and non-polar chlorophenols from tap, river and well water. The sorbent was found to be reusable for at least six times.

Wu et al. developed a mixed hemimicelles MSPE method for the extraction of cephalosporins from biological samples based on ionic liquid-coated magnetic graphene oxide nanoparticles prior to their determination by HPLC-UV [124]. For the fabrication of the modified sorbent, $\mathrm{GO} / \mathrm{Fe}_{3} \mathrm{O}_{4}$ nanoparticles were treated with 1-hexadecyl-3-methylimidazoliumbromide in a phosphate buffer solution ( $\mathrm{pH} \mathrm{7.0)}$ and the mixture was subjected to ultrasonic mixing $5 \mathrm{~min}$. Due to the $\pi-\pi$ stacking, the hydrophobic and the electrostatic interactions between the mixed hemimicelles and analytes, the modified material exhibited high surface area and excellent adsorption capacity. Moreover, after the extraction and desorption cycle, it is possible to regenerate the $\mathrm{GO} / \mathrm{Fe}_{3} \mathrm{O}_{4}$ with water and methanol. A decrease in the sorbent amount was observed after six cycles, however no significant loss of the sorption capacity occurred.

A three-dimensional ionic liquid functionalized magnetic $\mathrm{GO} / \mathrm{Fe}_{3} \mathrm{O}_{4}$ nanocomposite was prepared and used for the MSPE of PAHs from vegetable oil prior to their determination by GC-MS [125]. The ionic-liquid modified sorbent was prepared with a one-pot solvothermal method with 1-(3-aminopropyl)-3-methylimidazolium bromide. Subsequently, free-radical copolymerization took place to form a porous and 3D structure. After modification, the modified material exhibited high adsorption toward PAHs due to strong $\pi-\pi$ bonds between the sorbent and the analytes, as well as good mechanical stability and excellent reusability (for at least five times).

Lamei et al. evaluated different DESs, based on choline chloride $(\mathrm{ChCl})$ for the modification of $\mathrm{GO} / \mathrm{Fe}_{3} \mathrm{O}_{4}$, in order to develop a MSPE sorbent for the preconcentration of methadone in biological and water samples followed by GC-FID and GC-MS [126]. For this purpose, choline chloride was used as hydrogen bond acceptor and phenol, glycerol, and 5,6,7,8-tetrahydro-5,5,8,8-tetramethylnaphthalen-2-ol (TNO) as hydrogen-bond donors. The modified nanocomposites were prepared by mixing the DES and the $\mathrm{GO} / \mathrm{Fe}_{3} \mathrm{O}_{4}$ in a round-bottomed flask under stirring at room temperature for $1 \mathrm{~h}$. The highest extraction recovery for methadone was observed with the TNO hydrogen-bond donors at a molar ratio of 1:2. of $\mathrm{ChCl}$ :TNO. The developed methods exhibited high preconcentration factor and satisfactory extraction recovery, however no reusability data were reported.

\section{Conclusions}

Due to the sufficient surface area and its superparamagnetic properties, magnetic graphene oxide has successfully been employed for the extraction of a wide variety of organic compounds from environmental, food, biological and agricultural samples. The surface of magnetic $\mathrm{GO} / \mathrm{Fe}_{3} \mathrm{O}_{4}$ nanocomposite contains a large amount of hydroxyl and carboxyl groups, which assist the interaction between the sorbent and organic molecules through $\pi-\pi$ stacking, hydrophobic interaction as well as hydrogen bonding. In most MSPE methods, the $\mathrm{GO} / \mathrm{Fe}_{3} \mathrm{O}_{4}$ sorbent was found to be reusable after the desorption step, indicating satisfactory stability of the materials. Moreover, the synthetic procedures for the preparation of magnetic graphene oxide are simple, mild, rapid and economic. 
The main limitation of graphene oxide-based adsorbents is aggregation and restacking of the nanosheets, which may lead to blocking of the active adsorption sites of the sorbent, as well as to the reduction of its specific surface area. A wide variety of functional groups have been employed to overcome this problem. Enhancement of the dispersibility of magnetic graphene oxide in hydrophobic media can be also achieved through functionalization with appropriate chemical groups. Functionalization of magnetic graphene oxide has been also employed in order to enhance the extraction efficiency of the nanocomposite by introducing compatible chemical molecules with high surface area. Moreover, by using functional groups that can selectively bind with various organic, inorganic and biological guest molecules such as $\beta$-cyclodextrin, the selectivity of the extraction towards the target analyte can be significantly improved.

Microporous organic polymers, molecular imprinted polymers, metal-organic frameworks, and zeolitic imidazole frameworks have been used in order to create nanocomposites with extraordinary properties. The resulted materials combined the advantages of magnetic graphene oxide and the chosen material and exhibited sufficient surface area, great extraction efficiency, ease in handling and separation and good stability.

Finally, modification of magnetic graphene oxide with ionic liquid and deep eutectic solvents can significantly enhance the extraction efficiency of the sorbent. In this case, the modification process is simple, rapid, and environmentally friendly since no toxic organic solvents are required. Moreover, magnetic procedures are energy and time saving, and they require only small quantities of solvents during extraction and elution steps; therefore, they play a key role in green analytical chemistry.

Funding: The research work was supported by the Hellenic Foundation for Research and Innovation (HFRI) under the HFRI PhD Fellowship grant (Fellowship Number: 138).

Conflicts of Interest: The authors declare no conflict of interest.

\section{References}

1. Samanidou, V. Trends in Microextraction Techniques for Sample Preparation. Separations 2017, 5, 1. [CrossRef]

2. Manousi, N.; Raber, G.; Papadoyannis, I. Recent Advances in Microextraction Techniques of antipsychotics in Biological Fluids Prior to Liquid Chromatography Analysis. Separations 2017, 4, 18. [CrossRef]

3. Filippou, O.; Bitas, D.; Samanidou, V. Green approaches in sample preparation of bioanalytical samples prior to chromatographic analysis. J. Chromatogr. B 2017, 1043, 44-62. [CrossRef] [PubMed]

4. Kissoudi, M.; Samanidou, V. Recent Advances in Applications of Ionic Liquids in Miniaturized Microextraction Techniques. Molecules 2018, 23, 1437. [CrossRef]

5. Manousi, N.; Zachariadis, G. Determination of Volatile Compounds in Nut-Based Milk Alternative Beverages by HS-SPME Prior to GC-MS Analysis. Molecules 2019, 24, 3091. [CrossRef]

6. Anthemidis, A.; Ioannou, K. Sequential injection ionic liquid dispersive liquid-liquid microextraction for thallium preconcentration and determination with flame atomic absorption spectrometry. Anal. Bioanal. Chem. 2012, 404, 685-691. [CrossRef]

7. Karageorgou, E.; Manousi, N.; Samanidou, V.; Kabir, A.; Furton, K. Fabric phase sorptive extraction for the fast isolation of sulfonamides residues from raw milk followed by high performance liquid chromatography with ultraviolet detection. Food Chem. 2016, 196, 428-436. [CrossRef]

8. Manousi, N.; Gomez-Gomez, B.; Madrid, Y.; Deliyanni, E.; Zachariadis, G. Determination of rare earth elements by inductively coupled plasma-mass spectrometry after dispersive solid phase extraction with novel oxidized graphene oxide and optimization with response surface methodology and central composite design. Microchem. J. 2019, 152, 104428. [CrossRef]

9. Giakisikli, G.; Anthemidis, A. Magnetic materials as sorbents for metal/metalloid preconcentration and/or separation. A review. Analyt. Chim. Acta 2013, 789, 1-16. [CrossRef]

10. Hemmati, M.; Rajabi, M.; Asghari, A. Magnetic nanoparticle based solid-phase extraction of heavy metal ions: A review on recent advances. Microchim. Acta 2018, 185. [CrossRef] 
11. Ahmadi, F.; Rajabi, M.; Faizi, F.; Rahimi-Nasrabadi, M.; Maddah, B. Magnetic solid-phase extraction of Zineb by C18-functionalised paramagnetic nanoparticles and determination by first-derivative spectrophotometry. Int. J. Environ. Anal. Chem. 2014, 94, 1123-1138. [CrossRef]

12. Filippou, O.; Deliyanni, E.; Samanidou, V. Fabrication and evaluation of magnetic activated carbon as adsorbent for ultrasonic assisted magnetic solid phase dispersive extraction of bisphenol A from milk prior to high performance liquid chromatographic analysis with ultraviolet detection. J. Chromatogr. A 2017, 1479, 20-31. [CrossRef] [PubMed]

13. Li, W.; Shi, Y. Recent advances and applications of carbon nanotubes based composites in magnetic solid-phase extraction. Trac Trends Anal. Chem. 2019, 118, 652-665. [CrossRef]

14. Chatzimitakos, T.; Samanidou, V.; Stalikas, C.D. Graphene-functionalized melamine sponges for microextraction of sulfonamides from food and environmental samples. J. Chromatogr. A 2017, 1522, 1-8. [CrossRef] [PubMed]

15. Ziaei, E.; Mehdinia, A.; Jabbari, A. A novel hierarchical nanobiocomposite of graphene oxide-magnetic chitosan grafted with mercapto as a solid phase extraction sorbent for the determination of mercury ions in environmental water samples. Anal. Chim. Acta 2014, 850, 49-56. [CrossRef] [PubMed]

16. Lin, S.; Gan, N.; Qiao, L.; Zhang, J.; Cao, Y.; Chen, Y. Magnetic metal-organic frameworks coated stir bar sorptive extraction coupled with GC-MS for determination of polychlorinated biphenyls in fish samples. Talanta 2015, 144, 1139-1145. [CrossRef]

17. Wang, M.; Gao, M.; Zhang, K.; Wang, L.; Wang, W.; Fu, Q.; Xia, Z.; Gao, D. Magnetic covalent organic frameworks with core-shell structure as sorbents for solid phase extraction of fluoroquinolones, and their quantitation by HPLC. Microchim. Acta 2019, 186. [CrossRef]

18. Huang, X.; Liu, Y.; Liu, H.; Liu, G.; Xu, X.; Li, L.; Lv, J.; Liu, Z.; Zhou, W.; Xu, D. Magnetic Solid-Phase Extraction of Dichlorodiphenyltrichloroethane and Its Metabolites from Environmental Water Samples Using Ionic Liquid Modified Magnetic Multiwalled Carbon Nanotube/Zeolitic Imidazolate Framework-8 as Sorbent. Molecules 2019, 24, 2758. [CrossRef]

19. Kyzas, C.Z.; Deliyanni, E.A.; Bikiaris, D.N.; Mitropoulos, A.C. Graphene composites as dye adsorbents: Review. Chem. Eng. Res. Des. 2018, 129, 75-88. [CrossRef]

20. Travlou, N.A.; Kyzas, C.Z.; Lazaridis, N.K.; Deliyanni, E.A. Functionalization of graphite oxide with magnetic chitosan for the preparation of a nanocomposite dye adsorbent. Langmuir. 2013, 29, 1657-1668. [CrossRef]

21. Hummers, W.; Offeman, R. Preparation of Graphitic Oxide. J. Am. Chem. Soc. 1958, 80, 1339. [CrossRef]

22. Kyzas, G.Z.; Travlou, N.A.; Kalogirou, O.; Deliyanni, E. Magnetic graphene oxide: Effect of preparation route on Reactive Black 5 adsorption. Materials 2013, 6, 1360-1376. [CrossRef] [PubMed]

23. Kyzas, G.Z.; Deliyanni, E.; Matis, K.A. Graphene oxide and its application as adsorbent to waste water treatment. J. Chem. Technol. Biotechnol 2014, 89, 196-205. [CrossRef]

24. Rekos, K.; Kampouraki, Z.C.; Sarafidis, C.; Samanidou, V.; Deliyanni, E. Graphene Oxide Based Magnetic Nanocomposites with Polymers as Effective Bisphenol-A Nanoadsorbents. Materials 2019, 12, 1987. [CrossRef] [PubMed]

25. Smith, A.T.; LaChance, A.M.; Zeng, S.; Liu, B.; Sun, L. Synthesis, properties, and applications of graphene oxide/reduced graphene oxide and their nanocomposites. Nano. Mater. Sci. 2019, 1, 31-47. [CrossRef]

26. Sun, J.; Liang, Q.; Han, Q.; Zhang, X.; Ding, M. One-step synthesis of magnetic graphene oxide nanocomposite and its application in magnetic solid phase extraction of heavy metal ions from biological samples. Talanta 2015, 132, 557-563. [CrossRef] [PubMed]

27. Kazemi, E.; Dadfarnia, S.; Haji Shabani, A. Dispersive solid phase microextraction with magnetic graphene oxide as the sorbent for separation and preconcentration of ultra-trace amounts of gold ions. Talanta 2015, 141, 273-278. [CrossRef]

28. AlKinani, A.; Eftekhari, M.; Gheibi, M. Ligandless dispersive solid phase extraction of cobalt ion using magnetic graphene oxide as an adsorbent followed by its determination with electrothermal atomic absorption spectrometry. Int. J. Environ. Anal. Chem. 2019, 1-18. [CrossRef]

29. Marcano, D.C.; Kosynkin, D.V.; Berlin, J.M.; Sinitskii, A.; Sun, Z.; Slesarev, A.; Alemany, L.B.; Lu, W.; Tour, J.M. Improved Synthesis of Graphene Oxide. ACS Nano 2010, 4, 4806-4814. [CrossRef]

30. Babaei, A.; Zeeb, M.; Es-haghi, A. Magnetic dispersive solid-phase extraction based on graphene oxide/ $\mathrm{Fe}_{3} \mathrm{O}_{4} @$ polythionine nanocomposite followed by atomic absorption spectrometry for zinc monitoring in water, flour, celery and egg. J. Sci. Food Agric. 2018, 98, 3571-3579. [CrossRef] 
31. Wen, Y.; Niu, Z.; Ma, Y.; Ma, J.; Chen, L. Graphene oxide-based microspheres for the dispersive solid-phase extraction of non-steroidal estrogens from water samples. J. Chromatogr. A 2014, 1368, 18-25. [CrossRef] [PubMed]

32. Han, Q.; Wang, Z.; Xia, J.; Chen, S.; Zhang, X.; Ding, M. Facile and tunable fabrication of $\mathrm{Fe}_{3} \mathrm{O}_{4} /$ graphene oxide nanocomposites and their application in the magnetic solid-phase extraction of polycyclic aromatic hydrocarbons from environmental water samples. Talanta 2012, 101, 388-395. [CrossRef] [PubMed]

33. Wu, J.; Xiao, D.; Zhao, H.; He, H.; Peng, J.; Wang, C.; Zhang, C.; He, J. A nanocomposite consisting of graphene oxide and $\mathrm{Fe}_{3} \mathrm{O}_{4}$ magnetic nanoparticles for the extraction of flavonoids from tea, wine and urine samples. Microchim. Acta 2015, 182, 2299-2306. [CrossRef]

34. Zeng, S.; Gan, N.; Weideman-Mera, R.; Cao, Y.; Li, T.; Sang, W. Enrichment of polychlorinated biphenyl 28 from aqueous solutions using $\mathrm{Fe}_{3} \mathrm{O}_{4}$ grafted graphene oxide. Chem. Eng. J. 2013, 218, 108-115. [CrossRef]

35. Chen, X.; Hai, X.; Wang, J. Graphene/graphene oxide and their derivatives in the separation/isolation and preconcentration of protein species: A review. Anal. Chim. Acta 2016, 922,1-10. [CrossRef]

36. Sitko, R.; Zawisza, B.; Malicka, E. Graphene as a new sorbent in analytical chemistry. Trac Trends Anal. Chem. 2013, 51, 33-43. [CrossRef]

37. Ibrahim, W.; Nodeh, H.; Sanagi, M. Graphene-Based Materials as Solid Phase Extraction Sorbent for Trace Metal Ions, Organic Compounds, and Biological Sample Preparation. Crit. Rev. Anal. Chem. 2015, 46, 267-283. [CrossRef]

38. Liu, Q.; Shi, J.; Jiang, G. Application of graphene in analytical sample preparation. Trac Trends Anal. Chem. 2012, 37, 1-11. [CrossRef]

39. Ye, N.; Shi, P. Applications of Graphene-Based Materials in Solid-Phase Extraction and Solid-Phase Microextraction. Sep. Purif. Rev. 2014, 44, 183-198. [CrossRef]

40. Zhang, X.; Zhang, J.; Li, W.; Yang, Y.; Qin, P.; Zhang, X.; Lu, M. Magnetic graphene oxide nanocomposites as the adsorbent for extraction and pre-concentration of azo dyes in different food samples followed by high-performance liquid chromatography analysis. Food Addit. Contam. A 2018, 35, 2099-2110. [CrossRef]

41. Costa dos Reis, L.; Vidal, L.; Canals, A. Graphene oxide $/ \mathrm{Fe}_{3} \mathrm{O}_{4}$ as sorbent for magnetic solid-phase extraction coupled with liquid chromatography to determine 2,4,6-trinitrotoluene in water samples. Anal. Bioanal. Chem. 2017, 409, 2665-2674. [CrossRef] [PubMed]

42. Wu, L.; Yu, L.; Ding, X.; Li, P.; Dai, X.; Chen, X.; Zhou, H.; Bai, Y.; Ding, J. Magnetic solid-phase extraction based on graphene oxide for the determination of lignans in sesame oil. Food Chem. 2017, 217, 320-325. [CrossRef] [PubMed]

43. Pashaei, Y.; Ghorbani-Bidkorbeh, F.; Shekarchi, M. Superparamagnetic graphene oxide-based dispersive-solid phase extraction for preconcentration and determination of tamsulosin hydrochloride in human plasma by high performance liquid chromatography-ultraviolet detection. J. Chromatogr. A 2017, 1499, 21-29. [CrossRef] [PubMed]

44. Taghvimi, A.; Hamishehkar, H.; Ebrahimi, M. Magnetic nano graphene oxide as solid phase extraction adsorbent coupled with liquid chromatography to determine pseudoephedrine in urine samples. J. Chromatogr. B 2016, 1009-1010, 66-72. [CrossRef] [PubMed]

45. Lu, Q.; Guo, H.; Zhang, Y.; Tang, X.; Lei, W.; Qi, R.; Chu, J.; Li, D.; Zhao, Q. Graphene oxide-Fe $\mathrm{O}_{4}$ nanocomposite magnetic solid phase extraction followed by UHPLC-MS/MS for highly sensitive determination of eight psychoactive drugs in urine samples. Talanta 2019, 206, 120212. [CrossRef] [PubMed]

46. Taghvimi, A.; Hamishehkar, H.; Ebrahimi, M. The application of magnetic nano graphene oxide in determination of methamphetamine by high performance liquid chromatography of urine samples. J. Iran. Chem. Soc. 2016, 13, 1471-1480. [CrossRef]

47. Zhu, L.; Xu, H. Magnetic graphene oxide as adsorbent for the determination of polycyclic aromatic hydrocarbon metabolites in human urine. J. Sep. Sci. 2014, 37, 2591-2598. [CrossRef]

48. Zhang, X.; Ma, X.; Li, X.; Li, C.; Wang, R.; Chen, M. Development of Ultra-sensitive Method for Determination of Trace Atrazine Herbicide in Environmental Water Using Magnetic Graphene Oxide-Based Solid-Phase Extraction Coupled with Dispersive Liquid-Liquid Microextraction Prior to Gas Chromatography-Mass Spectrometry. Water Air Soil Poll. 2018, 229.

49. Ma, L.; Huang, J.; Zhou, M. Magnetic graphene oxide for efficient solid phase extraction of DEHP. IOP Conf. Ser. Mater. sci. eng. 2019, 544, 012063. [CrossRef] 
50. Zhang, L.; Zhang, Y.; Tang, Y.; Li, X.; Zhang, X.; Li, C.; Xu, S. Magnetic solid-phase extraction based on $\mathrm{Fe}_{3} \mathrm{O}_{4}$ /graphene oxide nanoparticles for the determination of malachite green and crystal violet in environmental water samples by HPLC. Int. J. Environ. Anal. Chem. 2018, 98, 215-228. [CrossRef]

51. Arvand, M.; Masouleh, A. Magnetic solid-phase extraction of imatinib and doxorubicin as cytostatic drugs by $\mathrm{Fe}_{3} \mathrm{O}_{4}$ /graphene oxide nanocomposite. J. Iran. Chem. Soc. 2017, 14, 1673-1682. [CrossRef]

52. Shi, P.; Ye, N. Magnetite-graphene oxide composites as a magnetic solid-phase extraction adsorbent for the determination of trace sulfonamides in water samples. Anal. Methods 2014, 6, 9725-9730. [CrossRef]

53. Wang, Y.; Liu, L.; Xiao, C.; Chen, L.; Yang, P.; Liu, Q.; Wang, J.; Liu, X. Rapid Determination of Trace Sulfonamides in Milk by Graphene Oxide-Based Magnetic Solid Phase Extraction Coupled with HPLC-MS/MS. Food Anal. Methods 2016, 9, 2521-2530. [CrossRef]

54. Li, Z.; Li, Y.; Qi, M.; Zhong, S.; Wang, W.; Wang, A.; Chen, J. Graphene- $\mathrm{Fe}_{3} \mathrm{O}_{4}$ as a magnetic solid-phase extraction sorbent coupled to capillary electrophoresis for the determination of sulfonamides in milk. J. Sep. Sci. 2016, 39, 3818-3826. [CrossRef] [PubMed]

55. Kazemi, E.; Dadfarnia, S.; Haji Shabani, A.; Abbasi, A.; Rashidian Vaziri, M.; Behjat, A. Iron oxide functionalized graphene oxide as an efficient sorbent for dispersive micro-solid phase extraction of sulfadiazine followed by spectrophotometric and mode-mismatched thermal lens spectrometric determination. Talanta 2016, 147, 561-568. [CrossRef]

56. Wang, Y.; Wen, Y.; Ling, Y. Graphene Oxide-Based Magnetic Solid Phase Extraction Combined with High Performance Liquid Chromatography for Determination of Patulin in Apple Juice. Food Anal. Methods 2016, 10, 210-218. [CrossRef]

57. Xiao, R.; Zhang, X.; Zhang, X.; Niu, J.; Lu, M.; Liu, X.; Cai, Z. Analysis of flavors and fragrances by HPLC with $\mathrm{Fe}_{3} \mathrm{O}_{4} @ \mathrm{GO}$ magnetic nanocomposite as the adsorbent. Talanta 2017, 166, 262-267. [CrossRef]

58. Bo, Z.; Shuai, X.; Mao, S.; Yang, H.; Qian, J.; Chen, J.; Yan, J.; Cen, K. Green preparation of reduced graphene oxide for sensing and energy storage applications. Sci. Rep. 2014, 4. [CrossRef]

59. Yuan, Y.; Sun, N.; Yan, H.; Han, D.; Row, K. Determination of indometacin and acemetacin in human urine via reduced graphene oxide-based pipette tip solid-phase extraction coupled to HPLC. Microchim. Acta 2015, 183, 799-804. [CrossRef]

60. Chandra, V.; Park, J.; Chun, Y.; Lee, J.W.; Hwang, I.; Kim, K.S. Water-dispersible magnetite-reduced graphene oxide composites for arsenic removal. ACS Nano 2010, 4, 3979-3986. [CrossRef]

61. Ai, L.; Zhang, C.; Chen, Z. Removal of methylene blue from aqueous solution by a solvothermal-synthesized graphene/magnetite composite. J. Hazard. Mater. 2011, 192, 1515-1524. [CrossRef]

62. Gao, Y.; Ma, D.; Wang, C.; Guan, J.; Bao, X. Reduced graphene oxide as a catalyst for hydrogenation of nitrobenzene at room temperature. Chem. Commun. 2011, 47, 2432-2434. [CrossRef] [PubMed]

63. Rowley-Neale, S.; Randviir, E.; Abo Dena, A.; Banks, C. An overview of recent applications of reduced graphene oxide as a basis of electroanalytical sensing platforms. Appl. Mater. Today 2018, 10, 218-226. [CrossRef]

64. Qi, T.; Huang, C.; Yan, S.; Li, X.; Pan, S. Synthesis, characterization and adsorption properties of magnetite/reduced graphene oxide nanocomposites. Talanta 2015, 144, 1116-1124. [CrossRef] [PubMed]

65. Luo, X.; Wang, C.; Luo, S.; Dong, R.; Tu, X.; Zeng, G. Adsorption of As (III) and As (V) from water using magnetite $\mathrm{Fe}_{3} \mathrm{O}_{4}$-reduced graphite oxide- $\mathrm{MnO}_{2}$ nanocomposites. Chem. Eng. J. 2012, 187, 45-52. [CrossRef]

66. Yan, S.; Qi, T.; Chen, D.; Li, Z.; Li, X.; Pan, S. Magnetic solid phase extraction based on magnetite/reduced graphene oxide nanoparticles for determination of trace isocarbophos residues in different matrices. J. Chromatogr. A 2014, 1347, 30-38. [CrossRef]

67. Wang, Q.; Jiao, L.; Du, H.; Wang, Y.; Yuan, H. $\mathrm{Fe}_{3} \mathrm{O}_{4}$ nanoparticles grown on graphene as advanced electrode materials for supercapacitors. J. Power Sources 2014, 245, 101-106. [CrossRef]

68. Zhang, M.; Wang, M.; Hao, Y.; Shi, X.; Wang, X. Effective extraction and simultaneous determination of Sudan dyes from tomato sauce and chili-containing foods using magnetite/reduced graphene oxide nanoparticles coupled with high-performance liquid chromatography. J. Sep. Sci. 2016, 39, 1749-1756. [CrossRef] 
69. Li, D.; Ma, X.; Wang, R.; Yu, Y. Determination of trace bisphenol A in environmental water by high-performance liquid chromatography using magnetic reduced graphene oxide based solid-phase extraction coupled with dispersive liquid-liquid microextraction. Anal. Bioanal.l Chem. 2016, 409, 1165-1172. [CrossRef]

70. Mehdinia, A.; Rouhani, S.; Mozaffari, S. Microwave-assisted synthesis of reduced graphene oxide decorated with magnetite and gold nanoparticles, and its application to solid-phase extraction of organochlorine pesticides. Microchim. Acta 2016, 183, 1177-1185. [CrossRef]

71. Li, N.; Chen, J.; Shi, Y. Magnetic polyethyleneimine functionalized reduced graphene oxide as a novel magnetic sorbent for the separation of polar non-steroidal anti-inflammatory drugs in waters. Talanta 2019, 191, 526-534. [CrossRef] [PubMed]

72. Li, N.A.; Chen, Y.; Shi, Y. Magnetic polyethyleneimine functionalized reduced graphene oxide as a novel magnetic solid-phase extraction adsorbent for the determination of polar acidic herbicides in rice. Anal. Chim. Acta 2017, 949, 23-34. [CrossRef] [PubMed]

73. Feng, Y.; $\mathrm{Hu}, \mathrm{X}$; Zhao, F.; Zeng, B. $\mathrm{Fe}_{3} \mathrm{O}_{4} /$ reduced graphene oxide-carbon nanotubes composite for the magnetic solid-phase extraction and HPLC determination of sulfonamides in milk. J. Sep. Sci. 2019, 42, 1058-1066. [PubMed]

74. Pinsrithong, S.; Bunkoed, O. Hierarchical porous nanostructured polypyrrole-coated hydrogel beads containing reduced graphene oxide and magnetite nanoparticles for extraction of phthalates in bottled drinks. J. Chromatogr. A 2018, 1570, 19-27. [CrossRef]

75. Mahpishanian, S.; Sereshti, H. One-step green synthesis of $\beta$-cyclodextrin/iron oxide-reduced graphene oxide nanocomposite with high supramolecular recognition capability: Application for vortex-assisted magnetic solid phase extraction of organochlorine pesticides residue from honey samples. J. Chromatogr. A. 2017, 1485, $32-43$.

76. Akbarzade, S.; Chamsaz, M.; Rounaghi, G.; Ghorbani, M. Zero valent Fe-reduced graphene oxide quantum dots as a novel magnetic dispersive solid phase microextraction sorbent for extraction of organophosphorus pesticides in real water and fruit juice samples prior to analysis by gas chromatography-mass spectrometry. Anal. Bioanal. Chem. 2017, 410, 429-439.

77. Yilmaz, E.; Ulusoy, H.; Demir, Ö.; Soylak, M. A new magnetic nanodiamond/graphene oxide hybrid $\left(\mathrm{Fe}_{3} \mathrm{O}_{4} @ \mathrm{ND} @ \mathrm{GO}\right)$ material for pre-concentration and sensitive determination of sildenafil in alleged herbal aphrodisiacs by HPLC-DAD system. J. Chromatogr. B 2018, 1084, 113-121. [CrossRef]

78. Musevi, S.; Mohammad-Rezaei, R.; Razmi, H. Magnetic solid-phase extraction of malachite green using soluble eggshell membrane protein doped with magnetic graphene oxide nanocomposite. Int. J. Environ. Anal. Chem. 2018, 98, 1242-1252. [CrossRef]

79. Lotfi, Z.; Mousavi, H.; Sajjadi, S. Amino-terminated hyper-branched polyamidoamine polymer grafted magnetic graphene oxide nanosheets as an efficient sorbent for the extraction of selective serotonin reuptake inhibitors from plasma samples. Anal. Methods 2017, 9, 4504-4513. [CrossRef]

80. Shi, P.; Ye, N. Investigation of the adsorption mechanism and preconcentration of sulfonamides using a porphyrin-functionalized $\mathrm{Fe}_{3} \mathrm{O}_{4}$-graphene oxide nanocomposite. Talanta 2015, 143, 219-225. [CrossRef]

81. Pan, S.; Zhou, L.; Zhao, Y.; Chen, X.; Shen, H.; Cai, M.; Jin, M. Amine-functional magnetic polymer modified graphene oxide as magnetic solid-phase extraction materials combined with liquid chromatography-tandem mass spectrometry for chlorophenols analysis in environmental water. J. Chromatogr. A 2014, 1362, $34-42$. [CrossRef] [PubMed]

82. Amiri, A.; Baghayeri, M.; Sedighi, M. Magnetic solid-phase extraction of polycyclic aromatic hydrocarbons using a graphene oxide/ $\mathrm{Fe}_{3} \mathrm{O}_{4} @$ polystyrene nanocomposite. Microchim. Acta 2018, 185. [CrossRef] [PubMed]

83. Amiri, A.; Baghayeri, M.; Hamidi, E. Poly(pyrrole-co-aniline)@graphene oxide/ $\mathrm{Fe}_{3} \mathrm{O}_{4}$ sorbent for the extraction and preconcentration of polycyclic aromatic hydrocarbons from water samples. New, J. Chem. 2018, 42, 16744-16751. [CrossRef]

84. Daryakenary, M.; Zeeb, M. Trace determination of chlorpheniramine in human plasma using magnetic dispersive solid-phase extraction based on a graphene oxide $/ \mathrm{Fe}_{3} \mathrm{O}_{4} @$ polythionine nanocomposite combined with high-performance liquid chromatography. RSC Adv. 2017, 7, 53210-53218. [CrossRef]

85. Zeeb, M.; Farahani, H. Graphene oxide/ $\mathrm{Fe}_{3} \mathrm{O}_{4} @$ polythionine nanocomposite as an efficient sorbent for magnetic solid-phase extraction followed by high-performance liquid chromatography for the determination of duloxetine in human plasma. Chem. Pap. 2017, 72, 15-27. [CrossRef] 
86. Ji, W.; Zhang, M.; Duan, W.; Wang, X.; Zhao, H.; Guo, L. Phytic acid-stabilized super-amphiphilic $\mathrm{Fe}_{3} \mathrm{O}_{4}$-graphene oxide for extraction of polycyclic aromatic hydrocarbons from vegetable oils. Food Chem. 2017, 235, 104-110. [CrossRef]

87. Abdolmohammad-Zadeh, H.; Talleb, Z. Magnetic solid phase extraction of gemfibrozil from human serum and pharmaceutical wastewater samples utilizing a $\beta$-cyclodextrin grafted graphene oxide-magnetite nano-hybrid. Talanta 2015, 134, 387-393. [CrossRef]

88. Chen, X.; Pan, S.; Ye, M.; Li, X.; Zhao, Y.; Jin, M. Magnetic solid-phase extraction based on a triethylenetetramine-functionalized magnetic graphene oxide composite for the detection of ten trace phenolic environmental estrogens in environmental water. J. Sep. Sci. 2016, 39, 762-768. [CrossRef]

89. Cheng, Z.; Du, F.; Qin, Q.; Sun, L.; Zeng, Q.; Ruan, G.; Li, J. Graphene oxide composites for magnetic solid-phase extraction of trace cytokinins in plant samples followed by liquid chromatography-tandem mass spectrometry. J. Sep. Sci. 2018, 41, 2386-2392. [CrossRef]

90. Markus, A.; Gbadamosi, A.; Yusuff, A.; Agi, A.; Oseh, J. Magnetite-sporopollenin/graphene oxide as new preconcentration adsorbent for removal of polar organophosphorus pesticides in vegetables. Environ. Sci. Poll. Res. 2018, 25, 35130-35142. [CrossRef]

91. Mahpishanian, S.; Sereshti, H.; Baghdadi, M. Superparamagnetic core-shells anchored onto graphene oxide grafted with phenylethyl amine as a nano-adsorbent for extraction and enrichment of organophosphorus pesticides from fruit, vegetable and water samples. J. Chromatogr. A 2015, 1406, 48-58. [CrossRef] [PubMed]

92. Kechagia, M.; Samanidou, V.; Kabir, A.; Furton, K.G. One-pot synthesis of a multi-template molecularly imprinted polymer for the extraction of six sulfonamide residues from milk before high-performance liquid chromatography with diode array detection. J. Sep. Sci. 2018, 41, 723-731. [CrossRef] [PubMed]

93. Cormack, P.A.G.; Elorza, A.Z. Molecularly imprinted polymers: Synthesis and characterisation. J. Chromatogr. B 2004, 804(1), 173-182. [CrossRef] [PubMed]

94. Masqueè, N.; Marceè, R.M.; Borrull, F. Molecularly imprinted polymers: New tailor-made materials for selective solid-phase extraction. TrAC-Trends Anal. Chem. 2001, 20, 477-485. [CrossRef]

95. Ning, F.; Peng, H.; Li, J.; Chen, L.; Xiong, H. Molecularly Imprinted Polymer on Magnetic Graphene Oxide for Fast and Selective Extraction of 17 $\beta$-Estradiol. J. Agric. Food Chem. 2014, 62, 7436-7443. [CrossRef]

96. Barati, A.; Kazemi, E.; Dadfarnia, S.; Haji Shabani, A. Synthesis/characterization of molecular imprinted polymer based on magnetic chitosan/graphene oxide for selective separation/preconcentration of fluoxetine from environmental and biological samples. J. Ind. Eng. Chem. 2017, 46, 212-221. [CrossRef]

97. Yaghi, O.M.; Li, H. Hydrothermal synthesis of a metal-organic framework containing large rectangular channels. J. Am. Chem. Soc. 1995, 117, 10401-10402. [CrossRef]

98. Hashemi, B.; Zohrabi, P.; Raza, N.; Kim, K. Metal-organic frameworks as advanced sorbents for the extraction and determination of pollutants from environmental, biological, and food media. Trends Anal. Chem. 2017, 97, 65-82. [CrossRef]

99. Giannakoudakis, D.A.; Bandosz, T.J. Building MOF Nanocomposites with Oxidized Graphitic Carbon Nitride Nanospheres: The Effect of Framework Geometry on the Structural Heterogeneity. Molecules 2019, $24,4529$. [CrossRef]

100. Zhou, H.; Long, J.R.; Yaghi, O.M. Introduction to metal-organic frameworks. Chem. Rev. 2012, 112, $673-674$. [CrossRef]

101. Furukawa, H.; Cordova, K.E.; O'Keeffe, M.; Yagh, O.M. The chemistry and applications of metal-organic frameworks. Science. 2013, 341. [CrossRef] [PubMed]

102. Pourbahman, F.; Zeeb, M.; Monzavi, A.; Homami, S. Simultaneous trace monitoring of prokinetic drugs in human plasma using magnetic dispersive micro-solid phase extraction based on a new graphene oxide/metal-organic framework-74/ $\mathrm{Fe}_{3} \mathrm{O}_{4}$ /polytyramine nanoporous composite in combination with HPLC. Chem. Pap. 2019, 73, 3135-3150. [CrossRef]

103. Cao, X.; Jiang, Z.; Wang, S.; Hong, S.; Li, H.; Shao, Y.; She, Y.; Wang, J.; Jin, F.; Jin, M. One-pot synthesis of magnetic zeolitic imidazolate framework/grapheme oxide composites for the extraction of neonicotinoid insecticides from environmental water samples. J. Sep. Sci. 2017, 40, 4747-4756. [CrossRef] [PubMed]

104. Zhang, S.; Yao, W.; Zhou, C.; Wang, J.; Zhao, H. Fabrication of magnetic zeolitic imidazolate framework-7 supported graphene oxide for the extraction of fungicides from environmental water and soil samples. Int. J. Environ. Anal. Chem. 2019, 1-10. [CrossRef] 
105. Liu, G.; Li, L.; Huang, X.; Zheng, S.; Xu, D.; Xu, X.; Zhang, Y.; Lin, H. Determination of triazole pesticides in aqueous solution based on magnetic graphene oxide functionalized MOF-199 as solid phase extraction sorbents. Micropor. Mesopor. Mater. 2018, 270, 258-264. [CrossRef]

106. Hua, X.; Gao, G.; Pan, S. High-affinity graphene oxide-encapsulated magnetic Zr-MOF for pretreatment and rapid determination of the photosensitizers hematoporphyrin and hematoporphyrin monomethyl ether in human urine prior to UPLC-HRMS. Anal. Bioanal. Chem. 2018, 410, 7749-7764. [CrossRef]

107. Wang, X.; Ma, X.; Huang, P.; Wang, J.; Du, P.; Du, X.; Lu, X. Magnetic Cu-MOFs embedded within graphene oxide nanocomposites for enhanced preconcentration of benzenoid-containing insecticides. Talanta 2018, 181, 112-117. [CrossRef]

108. Shahrebabak, S.M.; Saber-Tehrani, M.; Faraji, M.; Shabanian, M.; Aberoomand-Azar, P. Simultaneous magnetic solid phase extraction of acidic and basic pesticides using triazine-based polymeric network modified magnetic nanoparticles/graphene oxide nanocomposite in water and food samples. Microchem. J. 2019, 146, 630-639. [CrossRef]

109. Jansen, J.C.; Esposito, E.; Fuoco, A.; Carta, M. Microporous Organic Polymers: Synthesis, Characterization, and Applications. Polymers 2019, 11, 844. [CrossRef]

110. Li, Q.; Razzaque, S.; Jin, S.; Tan, B. Morphology design of microporous organic polymers and their potential applications: An overview. Sci. China Chem. 2017, 60, 1056-1066. [CrossRef]

111. Cousins, K.; Zhang, R. Highly Porous Organic Polymers for Hydrogen Fuel Storage. Polymers 2019, 11, 690. [CrossRef] [PubMed]

112. Faraji, M.; Shabanian, M.; Aryanasab, F. Efficient removal of anionic dyes from aqueous media using newly in situ synthesized triazine-based nitrogen-rich network modified magnetic nanoparticles. J. Iran. Chem. Soc. 2018, 15, 733-741. [CrossRef]

113. Kaur, P.; Hupp, J.T.; Nguyen, S.T. Porous Organic Polymers in Catalysis: Opportunities and Challenges. ACS Catal. 2011, 1, 819-835. [CrossRef]

114. Zhang, Y.; Jin, S. Recent Advancements in the Synthesis of Covalent Triazine Frameworks for Energy and Environmental Applications. Polymers 2018, 11, 31. [CrossRef] [PubMed]

115. Zhou, L.; Hu, Y.; Li, G. Conjugated microporous polymers with built-in magnetic NPs for excellent enrichment of trace hydroxylated polycyclic aromatic hydrocarbons in human urine. Anal. Chem. 2016, 88, 6930-6938.

116. Yang, W.; Wu, X.; Liu, T.; Wang, T.; Hou, X. Triazine-based conjugated microporous polymer composite for magnetic solid phase extraction of 5-nitroimidazoles coupled with UPLC-MS/MS for quantification. Analyst 2018, 143, 5744-5753. [CrossRef]

117. Chatzimitakos, T.; Stalikas, C. Carbon-Based Nanomaterials Functionalized with Ionic Liquids for Microextraction in Sample Preparation. Separations 2017, 4, 14. [CrossRef]

118. Han, D.; Row, K.H. Recent applications of ionic liquids in separation technology. Molecules 2010, 15, $2405-2426$. [CrossRef]

119. Serrano, M.; Chatzimitakos, T.; Gallego, M.; Stalikas, C.D. 1-butyl-3-aminopropyl imidazolium functionalized graphene oxide as a nanoadsorbent for the simultaneous extraction of steroids and $\beta$-blockers via dispersive solid-phase microextraction. J. Chromatogr. A 2016, 1436, 9-18. [CrossRef]

120. Smith, E.; Abbott, A.; Ryder, K. Deep Eutectic Solvents (DESs) and Their Applications. Chem. Rev. 2014, 114, 11060-11082. [CrossRef]

121. Xu, K.; Wang, Y.; Ding, X.; Huang, Y.; Li, N.; Wen, Q. Magnetic solid-phase extraction of protein with deep eutectic solvent immobilized magnetic graphene oxide nanoparticles. Talanta 2016, 148, 153-162. [CrossRef] [PubMed]

122. Wasserscheid, P.; Welton, T. Ionic Liquids in Synthesis, 2nd ed.; Wiley-VCH: Berlin, Germany, 2003.

123. Cai, M.-Q.; Su, J.; Hu, J.-Q.; Wang, Q.; Dong, C.-Y.; Pan, S.-D.; Jin, M.-C. Planar graphene oxide-based magnetic ionic liquid nanomaterial for extraction of chlorophenols from environmental water samples coupled with liquid chromatography-tandem mass spectrometry. J. Chromatogr. A 2016, 1459, 38-46. [CrossRef]

124. Wu, J.; Zhao, H.; Xiao, D.; Chuong, P.; He, J.; He, H. Mixed hemimicelles solid-phase extraction of cephalosporins in biological samples with ionic liquid-coated magnetic graphene oxide nanoparticles coupled with high-performance liquid chromatographic analysis. J. Chromatogr. A 2016, 1454, 1-8. [CrossRef] [PubMed] 
125. Zhang, Y.; Zhou, H.; Zhang, Z.; Wu, X.; Chen, W.; Zhu, Y.; Fang, C.; Zhao, Y. Three-dimensional ionic liquid functionalized magnetic graphene oxide nanocomposite for the magnetic dispersive solid phase extraction of 16 polycyclic aromatic hydrocarbons in vegetable oils. J. Chromatogr. A 2017, 1489, 29-38. [CrossRef] [PubMed]

126. Lamei, N.; Ezoddin, M.; Ardestani, M.S.; Abdi, K. Dispersion of magnetic graphene oxide nanoparticles coated with a deep eutectic solvent using ultrasound assistance for preconcentration of methadone in biological and water samples followed by GC-FID and GC-MS. Anal. Bioanal. Chem. 2017, 409, 6113-6121. [CrossRef]

(C) 2020 by the authors. Licensee MDPI, Basel, Switzerland. This article is an open access article distributed under the terms and conditions of the Creative Commons Attribution (CC BY) license (http://creativecommons.org/licenses/by/4.0/). 